\title{
A review on Phase Change Materials Integrated in Building Walls
}

Frédéric Kuznik $^{\mathrm{a}, *}$, Damien David ${ }^{\mathrm{a}}$, Kevyn Johannes ${ }^{\mathrm{a}}$, Jean-Jacques Roux ${ }^{\mathrm{a}}$

${ }^{a}$ Université de Lyon, CNRS

INSA-Lyon, CETHIL, UMR5008, F-69621, Villeurbanne, France

Université Lyon 1, F-69622, France

\begin{abstract}
The present paper is the first comprehensive review of the integration of phase change materials in building walls. Many considerations are discussed in this paper including physical considerations about building envelop and phase change material, phase change material integration and thermophysical properties measurements and various experimental and numerical studies concerning the integration. Even if the integrated phase change material have a good potential for reducing energy demand, further investigations are needed to really assess their use.

Keywords: Thermal Energy Storage, Phase Change Material, Building Envelop.
\end{abstract}

\section{Contents}

1 Introduction

2 Source of articles and categories

\footnotetext{
*Corresponding author. Tel.: +33-472-438-461; Fax: +33-472-438-522

Email address: frederic.kuznik@insa-lyon.fr (Frédéric Kuznik)
} 
2.1 Source of articles . . . . . . . . . . . . . . . . . 4

2.2 Categories of articles ................ 5

3 Integration of PCM in building envelop: physical considera$\begin{array}{ll}\text { tions and heuristic arguments } & 6\end{array}$

3.1 Physical considerations . . . . . . . . . . . . . 6

3.2 Heuristic arguments . . . . . . . . . . . . . . . 8

4 Phase change theory $\quad 9$

4.1 The phase change of a pure ideal body . . . . . . . . . . . 9

4.2 The phase change of a mixture . . . . . . . . . . . . . 13

5 Phase change materials used in building walls $\quad 15$

5.1 Organic PCM . . . . . . . . . . . . . . . . 15

5.2 Inorganic PCM . . . . . . . . . . . . . . . 17

$\begin{array}{llr}6 & \text { PCM containment } & 19\end{array}$

6.1 The impregnation of building materials . . . . . . . . . . . . . 19

6.2 The micro-encapsulation . . . . . . . . . . . . . 20

6.3 Shape Stabilized PCM . . . . . . . . . . . . . . . . 21

6.4 Other containers . . . . . . . . . . . . . . . 22

7 Measurement of the thermal properties of a PCM and PCMIBW 23

7.1 DSC: Differential Scanning Calorimetry . . . . . . . . . 23

7.2 The T-history method . . . . . . . . . . . 25

7.3 The guarded hot-plate setup . . . . . . . . . . . . . . . 26

8 Experimental studies $\quad 26$ 


\section{Introduction}

As demand in thermal comfort of buildings rise increasingly, the energy consumption is correspondingly increasing. For example, in France, the energy consumption of buildings has increased by $30 \%$ the last 30 years. Housing and tertiary buildings are responsible for the consumption of approximatively $46 \%$ of all energies and approximatively $19 \%$ of the total $\mathrm{CO}_{2}$ emissions [1]. Nowadays, thermal energy storage systems are essential for reducing dependency on fossil fuels and then contributing to a more efficient environmentally benign energy use [2].

Thermal energy storage can be accomplished either by using sensible heat storage or latent heat storage. Sensible heat storage has been used for centuries by builders to store/release passively thermal energy, but a much larger volume of material is required to store the same amount of energy in comparison to latent heat storage. The principle of the phase change material $(\mathrm{PCM})$ use is simple. As the temperature increases, the material changes phase from solid to liquid. The reaction being endothermic, the PCM absorbs heat. Similarly, when the temperature decreases, the material changes phase from liquid to solid. The reaction being exothermic, the PCM desorbs heat. The integration of PCM in building walls is a way to enhance the storage capacity of building envelop and then to rationalize the use of renewable and non-renewable energies. 
The number of articles concerning the PCM integration in building walls (PCMIBW) has increased during the last five years. Then, this paper is dedicated to a review of such PCMIBW. So, the part 2 deals with a factual analysis of the papers from the literature. Some physical considerations concerning PCMIBW and heuristic arguments are given in part 3. The part 4 deals with some basics of phase change theory which is very important for the understanding of heat transfers. A review of PCM studied in the literature is developed in the part 5. The integration of PCM highly depends on the containment, then the part 6 deals with this specific problem. The part 7 deals with the measurement of PCM and PCMIBW thermophysical properties. The parts 8 and 9 of the paper are respectively dedicated to a review of experimental and numerical studies concerning PCMIBW.

\section{Source of articles and categories}

\subsection{Source of articles}

Conference papers have been voluntarily omitted to avoid any duplications. Figure 1 shows the distribution of the number of articles since 1979. Three phases can be distinguished: around 1980, between 1990 and 2000 and after 2003. The first studies dealing with PCM integration into building walls are dated from the 80's (3 publications). Then, during the period between 1980 and 1990, only 2 articles have been published. From 1990 to 2000, the number of publications per year increase to about 1 publication per year. After 2003, an increase in the number of publications occurred (reaching up to 14 articles). Almost $80 \%$ of the studies have been carried out over the past 8 years which have seen the development of new encapsulation technologies 
and new energy standards. However, this analysis should take into account the fact that the number of articles per journal has increased significantly since 1979.

Figure 2 presents the distribution of the studies per journal. Most of the publications (51\%) come from three journals. Furthermore, almost $85 \%$ of the articles have been published by the same publisher.

As an example, the journal shown in figure 2 that published 33 articles, has multiplied by 4.3 the number of papers published between 1979 (38 papers) and 2009 (164 papers). The same kind of observation can be made for the other journals. Finally, it is possible to conclude that interest in the subject rising, because the number of publications has risen by a factor of 12 .

The distribution of the publications per country is shown in figure 3. The origin of the articles can be diverse depending on the authors affiliation. As a consequence, the total number of studies in figure 3 is greater than the total number of articles collected in this paper (99 articles but all of them are not cited in the present paper). More than $17 \%$ of the articles have been published by China.

\subsection{Categories of articles}

The review articles represent about $10 \%$ of the total amount of papers (9 review articles [3-11]). All of these articles deal with the general problem of thermal energy storage using PCM and no only the case of PCM walls.

Removing the review articles from the list, the identified categories concerning the publications are: 
$\Rightarrow 41 \%$ of publications deals only with experimental studies; $26 \%$ of these papers are dedicated to the development and evaluation of PCM walls only.

$\Rightarrow 38 \%$ of publications are dedicated to the numerical evaluation of PCM walls.

$\Rightarrow 21 \%$ of the publications deals with both experiment and numerical modeling.

It is interesting to note that no study, experimental or numerical, examines the evaluation of PCM walls in real conditions i.e. with internal loads.

\section{Integration of PCM in building envelop: physical considerations and heuristic arguments}

\subsection{Physical considerations}

The building is a quite complex object submitted to internal and external solicitations (see figure 4). External solicitations are due to the local external weather. Internal solicitations come from solar radiative flux entering the building and internal loads. A high energy efficiency building must have an energy efficient envelop that can ensure comfort of occupants with a minimum system energy requirement. From this point of view, thermal energy storage in the envelop is a key factor.

Inside a building room, the heat transfer processes between the surface of the wall and the solicitations are:

* convective heat transfer between the air and the surface, 
* shortwave radiative heat transfer,

* longwave radiative heat transfer.

The heat transfer in the wall is conduction. Outside the envelop, the heat transfer processes are the same as inside the building room.

The effect of thermal energy storage in the building envelop is to reduce the indoor temperature fluctuations and to delay the air temperature extremum. Thermal energy is usually stored in the building envelop by sensible heat of the materials. The storage capacity is related to the mass-specific heat capacity and the mass of the materials used in the building envelop. Of course, the storage capacity of the envelop is also related to the composition of the walls and the technological solutions. For example, a wall composed of concrete with external insulation have a higher storage capacity than the same wall with internal insulation.

For example, light weight building have low thermal energy storage capacity because of the materials used for the envelop. In that case, integration of PCM enhances the storage capacity (see figure 5): as the temperature increases, the material changes phase from solid to liquid and the PCM absorbs heat. Similarly, when the temperature decreases, the material changes phase from liquid to solid and the PCM desorbs heat. PCM can also be used to control the air temperature: contrary to sensible heat storage, latent heat storage occurs at the phase change temperature without a significant raise in temperature.

On the whole, a high energy efficient building envelop must have the following characteristics: 
$\longrightarrow$ few thermal energy losses with the exterior by thermal insulation,

$\longrightarrow$ use of renewable energy using for example sun radiation through glazing windows,

\section{$\longrightarrow$ limitation of overheating or energy demand peaks using PCMIBW.}

\subsection{Heuristic arguments}

Using very simplified assumptions, Peippo et al. [12] presented approximate formulae for optimum phase change temperature and thickness of the PCMIBW:

$$
\begin{gathered}
T_{m, o p t}=\bar{T}_{r}+\frac{Q}{h t_{s t o r}} \\
D_{o p t}=\frac{t_{n} h}{\rho \Delta H}\left(T_{m, o p t}-T_{n}\right) \\
\bar{T}_{r}=\frac{t_{d} T_{d}+t_{n} T_{n}}{t_{d}+t_{n}}
\end{gathered}
$$

where:

$\triangleright T_{m, o p t}$ is the optimal phase change point of the $\mathrm{PCM}\left[{ }^{\circ} \mathrm{C}\right]$,

$\triangleright \bar{T}_{r}$ is the average room temperature $\left[{ }^{\circ} \mathrm{C}\right]$,

$\triangleright Q$ is the heat absorbed by unit area of the room surface $\left[\mathrm{J} / \mathrm{m}^{2}\right]$,

$\triangleright h$ is the average heat transfer coefficient between wall surface and surroundings $\left[W / m^{2} /{ }^{\circ} \mathrm{C}\right]$

$\triangleright T_{d}$ is the room daytime temperature $\left[{ }^{\circ} \mathrm{C}\right]$,

$\triangleright T_{n}$ is the room nighttime temperature $\left[{ }^{\circ} \mathrm{C}\right]$, 


$$
\begin{aligned}
& \triangleright t_{d} \text { is the charging time, day }[s], \\
& \triangleright t_{n} \text { is the discharging time, night }[s], \\
& \triangleright t_{\text {stor }} \text { is the diurnal storage, cycle }=t_{d}+t_{n}[s](24 \mathrm{~h}), \\
& \triangleright D_{o p t} \text { is the optimal thickness of the PCM slab }[\mathrm{m}], \\
& \triangleright \Delta H \text { is the latent heat of fusion of PCM }[\mathrm{J} / \mathrm{kg}] .
\end{aligned}
$$

\section{Phase change theory}

From a practical point of view, only the phase change solid-liquid is used in building envelop. The material can be a pure substance, an eutectic mixture or a non-eutectic mixture. The difference between eutectic and noneutectic mixture is the phase change temperature: for an eutectic mixture, the phase changes at a constant temperature whereas, for a non-eutectic mixture, the phase changes during a temperature interval. From the literature review, the phase change materials used have phase change temperature in the range $\left[20^{\circ} \mathrm{C}, 60^{\circ} \mathrm{C}\right]$.

\subsection{The phase change of a pure ideal body}

The exact definition of the phase of a pure body is "an area in the space of the thermodynamic parameters $(T, p, V)$ of a system composed uniquely of the pure body, in which the free energy is an analytical function".

Let's consider the volume $V$ of the system fixed. The areas occupied by each phase can be represented in a plan of which the abscissa is the temperature $T$ and the ordinate is the pressure $p$. This representation is commonly called the phase diagram, an example is drawn on the figure 6 . 
There are three phases on the diagram. When the pure body is at the thermodynamic equilibrium with a pressure $p_{0}$ and a temperature $T_{0}$, its phase is the phase 2 .

The matter can be found under several states. The three most common states are gas, liquid and solid. Generally, the state of the matter correspond directly to phase, that's why the terms "solid phase", "liquid phase", and "gas phase" are usually used.

The phase change which is usually used to store latent heat energy in buildings is between the liquid phase of the material and its solid phase. The liquid $\rightarrow$ solid transformation is called solidification and the solid $\rightarrow$ liquid transformation is called fusion.

The pressure can be considered as constant during the phase change in building applications; its value being equal to the atmospheric pressure $p_{a t m}$. If a transformation corresponding to a constant pressure $p=p_{\text {atm }}$ (horizontal line on the figure 7) is drawn on the phase diagram, this line intercepts the liquid-solid boundary. The temperature at this crossing is called the fusion temperature of a pure body. If $T \leq T_{f}$, the pure body at the thermodynamic equilibrium is solid. If $T \geq T_{f}$, the pure body at the thermodynamic equilibrium is liquid.

Now let's consider the phase change dynamics. The pure body is subjected to a temperature perturbation at a time $t$, it reaches its thermodynamic equilibrium at a time $t+\Delta t$. The change in thermodynamic equilibrium is mainly due to heat exchanges with the external environment. The time for the pure body to reach the new thermodynamic equilibrium is the time needed for the heat to be exchanged. 
The figures 8 show the time evolution of the temperature $T$ of the pure ideal body, and the time evolution of the heat flux $q$ leaving the body, if the external environment is subjected to a temperature step $\Delta T$, which leads to the solidification of the body. During the cooling there are three steps:

- 1 . The cooling of the liquid: The pure liquid body releases sensible heat and its temperature decreases until it reaches the temperature of fusion. The total amount of energy released is equal to $h_{l}=C_{p_{l}} \int_{T_{f}}^{T_{a}} d T$. $C_{p_{l}}$ is the heat capacity of the liquid phase. $h_{l}$ corresponds to the area under the heat flux curve.

- 2. The phase change: The latent heat is released. The temperature remains constant.

- 3. The cooling of the solid: The pure solid body releases sensible heat and its temperature decreases until it reaches the equilibrium temperature. The total amount of energy released is equal to $h_{s}=C_{p_{s}} \int_{T_{z}}^{T_{f}} d T$. $C_{p_{s}}$ is the heat capacity of the solid phase.

The curves of figure 8 depended on the thermal solicitation due to a modification of the external environment. When such a curve has to be examined, it is important to know the nature of the thermal solicitation. The most frequent graphics found in the literature are:

- Temperature Step response: The time evolution of the material's temperature due to an external temperature step (figure 8)

- Temperature scanning response: The evolution of the released heat flux as a function of the external temperature $T_{\text {ext }}$, when this temperature 
is following a ramp (scanning)(figure 9). Thus, the curve depends on the speed of the external temperature increase.

The latent heat of the material is obtained from the area under the curve and the external temperature speed $V_{T_{e x t}}=\frac{d T e x t}{d t}$, which is constant. The latent heat is deduced from the formula:

$$
h_{f}=\int_{t 1}^{t 2} q(t) d t=\int_{T e}^{T o} q\left(T_{e x t}\right) \cdot \frac{\partial t}{\partial T_{e x t}} d T_{e x t}=\frac{1}{V_{T_{e x t}}} \cdot A_{f}
$$

Then, some characteristic temperatures are necessary to enable quantitative comparison between different curves:

- $T_{i}$ and $T_{f}$ : initial and final temperatures respectively at the beginning and the end of the deviation from the sensible heat transfer curve.

- $T_{p}$ : peak temperature of the maximum heat flux.

- $T_{o}$ and $T_{e}$ : On each side of the maximum heat flux point, there is an inflexion of the curve. Tangents lines can be drawn at the inflexion points. Those temperatures are the temperatures at the intersection between the tangents ant the base of the curve i.e. onset temperature $T_{o}$ and end temperature $T_{e}$.

The most commonly used temperatures to get the characteristics of a PCM are $T_{p}, T_{o}$, and $\Delta T=T_{o}-T_{e}$, the width of the peak.

The solidification of a PCM begins with a nucleation effect. The nucleation is the formation of initial crystals, called nucleis. Then, the crystals propagate in the material to form the solid phase. The nucleation rate of a material is its capability to produce nucleus when the temperature decreases below the fusion temperature. 
If the nucleation rate of a material is too low, it can remain in the liquid phase when its temperature decreases below the fusion temperature. The solidification starts later: the material temperature rises again suddenly to the phase change temperature, as shown on the figure 10. This effect is called the supercooling effect and is very important when dealing with pure PCM.

\subsection{The phase change of a mixture}

This section is devoted to the physical description of the phase change of a binary mixture. Of course, for multi-components mixture, the theory is quite similar but more complicated from a representation point of view. The binary diagram is used to represent the location of the different phases of a mixture.

The figure 11 shows a binary diagram of an isomorphous system. The abscissa corresponds to the proportion of the component $B$ in the mixture $A+B$, and the ordinate is the temperature of the mixture. The volume and the pressure are constant.

The diagram consists of two single-phase fields separated by a two-phase field. The boundary between the liquid field and the two-phase field in figure 11 is called the liquidus; that between the two-phase field and the solid field is the solidus. In general, a liquidus is the locus of points in a phase diagram representing the temperatures at which mixtures of the various compositions of the system begin to freeze on cooling or finish melting on heating; a solidus is the locus of points representing the temperatures at which the various mixtures finish freezing on cooling or begin melting on heating. The phases in equilibrium across the two-phase field (the liquid and solid solutions) are called conjugate phases. 
Let's take the example of a binary mixture composition represented by line $(I)$. If the mixture is solid and the temperature increase, the melting begins at the temperature $T h$ (i.e. point $h$ ) and the composition is totally liquid at temperature $T c$ (i.e. point $c$ ). If the mixture is liquid and the temperature decrease, the solidification begins at the temperature $T c$ (i.e. point $c$ ) and the composition is totally solid at temperature $T h$ (i.e. point h). There is a hysteresis phenomenon in the phase change.

If the mixture is at temperature $T e$ (i.e. point $e$ ), the composition of the mixture is given by the location of points $f$ and $g$ :

$$
\begin{aligned}
& \frac{\overline{e g}}{\overline{f g}} \times 100 \%=\% \text { of solid present } \\
& \frac{\overline{f e}}{\overline{f g}} \times 100 \%=\% \text { of liquid present }
\end{aligned}
$$

Depending on the components, several phase diagram exist depending on the phase change behavior of the mixture. Figure 12 shows the phase diagram with a large solubility gap and a minima liquidus temperature e.g. an azeotropic point $X$.

The figure 13 shows the special case of a system with an eutectic mixture i.e. point $E$; it is a mixture at such proportions that melting point is as low as possible and that all the components crystallize simultaneously.

The figure 14 extract from [14] shows the experimental phase diagram of binary mixtures system of $\mathrm{C}_{14} \mathrm{H}_{30}$ and $\mathrm{C}_{16} \mathrm{H}_{34}$. The eutectic point $M$ of the mixture occurs at $91.67 \%$ of tetradecane, and the phase change temperature 
at this point is approximately $1.7^{\circ} \mathrm{C}$. Of course, the phase diagram is necessary to correctly model the heat stored/release but, presently, it is never used for building simulations.

\section{Phase change materials used in building walls}

The phase change materials used in building wall applications can be either organic materials or inorganic materials.

\subsection{Organic PCM}

The organic PCM are paraffins, fatty acids and the polyethylene glycol (PEG). They present a congruent phase change, they are not dangerous, and they have a good nucleation rate.

The table 1 presents the thermal properties of organic materials found in the literature, which may be suitable to the specification listed before. $T_{f}$ is the temperature of fusion, $H_{f}$ is the latent heat of fusion, $C p_{s}$ and $C p_{l}$ are the heat capacities of the solid and liquid phases, $k_{s}$ and $k_{l}$ is the thermal conductivity of the solid and liquid phase.

The advantages of organic PCM are:

- availability in a large temperature range,

○ freeze without much super cooling,

- ability to melt congruently,

○ self nucleating properties,

o compatibility with conventional material of construction, 


\begin{tabular}{llllllll}
\hline Materials & $T_{f}$ & $H_{f}$ & $C p_{s}$ & $C p_{l}$ & $k_{s}$ & $k_{l}$ & References \\
& ${ }^{\circ} \mathrm{C}$ & $k J / k g$ & $k J / k g / K$ & $k J / k g / K$ & $W / m^{2} / K$ & $W / m^{2} / K$ & \\
\hline \hline GR25 & $23.2-24.1$ & 45.3 & 1.2 & 1.2 & n.a. & n.a. & {$[15,16]$} \\
PEG600 & 22 & 127.2 & n.a. & 2.49 & n.a. & n.a. 0.189 & {$[15]$} \\
n-octadecane & 27 & 243.5 & 1.934 & 2.196 & 0.358 & 0.148 & {$[17]$} \\
n-eicosane & 37 & 241.0 & 2.01 & 2.04 & 0.15 & 0.15 & {$[17]$} \\
P116 & 47 & 225.0 & 2.4 & 1.9 & 0.24 & 0.24 & {$[17]$} \\
butyl stearate & 19 & 140.0 & n.a. & n.a. & n.a. & n.a. & {$[18,19]$} \\
ERMEST2325 & $17-20$ & 138 & n.a. & n.a. & n.a. & n.a. & {$[20,21]$} \\
RT27 & $28-26$ & 179 & 1.8 & 2.4 & 0.2 & 0.2 & {$[22-25]$} \\
MICRONAL26 & 26 & 110 & n.a. & n.a. & n.a. & n.a. & {$[24,26]$} \\
RT20 & 22 & 172 & n.a. & n.a. & n.a. & n.a. & {$[27]$} \\
MP25\%-MS35\% & $21.8-24.5$ & 175 & n.a. & n.a. & n.a. & n.a. & {$[28]$} \\
MP77\%-MS23\% & $22.4-23.8$ & 177 & n.a. & n.a. & n.a. & n.a. & {$[28]$} \\
MP93\%-MS7\% & $22.2-22.8$ & 182 & n.a. & n.a. & n.a. & n.a. & {$[28]$} \\
GR41 & 43 & 63 & n.a. & n.a. & 0.15 & 0.15 & {$[29]$} \\
GR27 & 28 & 72 & n.a. & n.a. & 0.15 & 0.15 & {$[29]$} \\
eutectic capric-myristic & 21.7 & 155 & n.a. & n.a. & n.a. & n.a. & {$[30]$} \\
MICRONAL5001 & 26 & 110 & n.a. & n.a. & n.a. & n.a. & {$[31]$} \\
MICRONAL5008 & 22 & 110 & n.a. & n.a. & n.a. & n.a. & {$[31]$} \\
heptadecane & 22 & 214 & n.a. & n.a. & n.a. & n.a. & {$[32]$} \\
MPCM28-D & 28 & $180-195$ & n.a. & n.a. & n.a. & n.a. & {$[33]$} \\
UNICERE55 & $45-60$ & 185 & n.a. & n.a. & n.a. & n.a. & {$[19]$} \\
n-nonadecane & 31.8 & 160 & n.a. & n.a. & n.a. & n.a. & {$[34]$} \\
eutectic capric-stearic & 24.7 & 179 & n.a. & n.a. & n.a. & n.a. & {$[35]$} \\
non-eutectic capric-lauric & $19.2-20.3$ & $144-150$ & n.a. & n.a. & n.a. & n.a. & {$[36]$} \\
U3 & 28 & 244 & n.a. & n.a. & 0.28 & 0.22 & {$[37]$} \\
U4 & $13.6-23.5$ & $104.5-107.5$ & 4 & 4.1 & 0.18 & 0.22 & {$[13,38-41]$} \\
RT25 & 25 & 147 & 2.9 & 2.1 & 1.02 & 0.56 & {$[42]$} \\
\hline & & & & & & & \\
\hline
\end{tabular}

Table 1: Organic PCM in literature (MP:methyl palmitate; MS:methyl stearate; U:unknown; n.a.: not available). 
○ no segregation,

○ chemically stable,

$\circ$ high heat of fusion,

$\circ$ safe and non-reactive,

○ recyclable.

The disadvantages of organic PCM are:

- low thermal conductivity,

- low volumetric latent heat storage capacity,

o flammable (depending on containment).

\subsection{Inorganic $P C M$}

The inorganic PCM are salt hydrates. The table 2 lists some inorganic PCM.

The advantages of inorganic PCM are:

○ high volumetric latent heat storage capacity,

○ low cost and easy availability,

- sharp phase change,

o high thermal conductivity,

○ non-flammable.

The disadvantages of inorganic PCM are: 


\begin{tabular}{llllllll}
\hline Materials & $T_{f}$ & $H_{f}$ & $C p_{s}$ & $C p_{j}$ & $k_{s}$ & $k_{l}$ & \multicolumn{2}{l}{ References } \\
& ${ }^{\circ} \mathrm{C}$ & $k J / k g$ & $k J / k g / K$ & $k J / k g / K$ & $W / m^{2} / K$ & $W / m^{2} / K$ & \\
\hline \hline eutectic salt & 32 & 216 & n.a. & n.a. & n.a. & n.a. & {$[43]$} \\
SP-25-A8 & $26-25$ & 180 & 2.5 & n.a. & 0.6 & 0.6 & {$[23]$} \\
calcium chloride hexahydrate & $26-29$ & 175 & 2.3 & 1.4 & 1 & 1 & {$[25]$} \\
sodium thiosulfate pentahydrate & $48-40$ & 210 & 1.46 & 2.4 & n.a. & n.a. & {$[44]$} \\
U1 & $30-32.5$ & 131 & n.a. & n.a. & n.a. & n.a. & {$[45,46]$} \\
U2 & $26-28$ & 188 & 1.44 & 1.44 & 1.09 & 0.54 & {$[47]$} \\
CaCl2.6H20 & 29.8 & 191 & n.a. & n.a. & n.a. & n.a. & {$[37]$} \\
S27 & 27 & 190 & 1.5 & 2.22 & 0.79 & 0.48 & {$[42]$} \\
L30 & 30 & 270 & 1.23 & 1.79 & 1.02 & 0.56 & {$[42]$} \\
\hline
\end{tabular}

Table 2: Inorganic PCM in literature (U:unknown). 
○ high volume change,

○ super cooling,

○ segregation.

\section{PCM containment}

\subsection{The impregnation of building materials}

The simplest method consists in the direct impregnation of the PCM into a gypsum, concrete or other porous materials to form mixed type PCMIBW. Khudhair et al. [48] explained the different impregnation techniques. The volume occupied by the PCM in the pores is small enough to prevent from the isolation of the solid PCM crust. The structure of the porous material transports the heat to the pores. Unfortunately, important leakage have been observed, in particularly by Xiao and al. [49]. Cabeza and al. [26] also reported an interaction between the PCM and its porous container. This interaction can deteriorate the mechanical properties of the container.

The materials used for impregnation are:

$\triangleright$ plaster: $[18,20,21,28,32,35,36,50-52]$

$\triangleright$ concrete: $[19,44,50]$

$\triangleright$ vermiculite: [30]

$\triangleright$ wood: [53]

$\triangleright$ cement: [34]

$\triangleright$ compound: [54-56] 


\subsection{The micro-encapsulation}

The micro-encapsulation consists in enclosing the PCM in a microscopic polymer capsule. The micro-capsules form a powder which is then included in the recipe of a building construction material. Special attention has to be taken in the choice of the capsule's material to avoid chemical reactions between the capsules and the building material. The PCM is trapped and can not leak anymore, and the size of the capsules is small enough to prevent from a disproportionate isolation of the solid crust of the PCM.

The quality of the process of micro-encapsulation is evaluated by the ration between the mass of the satisfying capsules (hermetic capsules containing PCM) and the total mass of the powder. Hawlader and al. [57] investigated the influence on this ratio of several parameters such as the duration of the process, the quantity of PCM and reticulation agent introduced in the solution, for a coacervation micro-encapsulation.

Three characteristics of the capsules are relevant to appreciate the quality of the powder: their mean diameter, the thickness of their shell, the mass percentage of PCM compared to the total mass of the capsule. For an in-situ polymerization, Zhang et al. [58] varied the strength of the beater, which caused a variation in the mean size of the capsules. Sarler et Onder [59] performed a statistical study on the size of the capsules to evaluate their degree of inhomogeneities in a powder.

The PCM powder has to be included into the mixture of a building material, such as concrete, a polymer or gypsum, to form the improved building phase change material. Thus, the thermal behavior of the PCMIBW depends on the thermal specifications of the building material. 
However, DSC measurements have been performed directly on the PCM powder to determine its specific latent heat and its temperature of fusion. Yamagishi and al. [60] observed a supercooling effect during the solidification of micro-encapsulated. When the size of the micro-capsules decreases below a few microns, the nucleation agents, which are necessary to the start of the solidification, rarefy. The solidification is delayed. Zhang and al. [58] attenuated the supercooling effect by adding nucleation agents into the PCM. The nucleation agent which they used were 1-tetradecanol for $C_{14}$ PCM, and 1-pentadecanol for $C_{15}$ PCM.

In the literature review, about 20 papers deals with micro-encapsulated PCM in building material, most of them being plaster material. For example, Schossig and al. [61] built gypsum boards containing micro-encapsulated $\mathrm{PCM}$, of which the temperature of fusion was around $25^{\circ} \mathrm{C}$. The figure 15 is a SEM photography of the PMC in the concrete.

\subsection{Shape Stabilized PCM}

Shape stabilized PCM are prepared from a liquid mixture of the PCM and a supporting material. The mixture is then cooled below the glass transition temperature of the supporting material, until it becomes solid. An appropriate choice of the supporting material allows PCM mass proportions up to $80 \%$. The figure 16 shows two pictures of a plate made of shape-stabilized PCM. On the first one, one can notice that the shape-stabilized PCM looks like a homogeneous material. The second picture shows the micro-structure of the material.

The most common supporting materials found in the literature are high density polyethylene (HDPE) and styrene-butadiene-styrene (SBS). Sari [62] 
did not observe any leakage of the phase change material by using HDPE as supporting material. Xiao and al. [49] made the same remark for SBS. Zhang and al. [56] report that the PCM mixes better into SBS than HDPE, but the shape-stabilized PCM is more rigid when using HDPE.

The thermal conductivity of a shape stabilized PCM is not very high, which is a problem in latent heat storage systems. Thus, researchers added some materials into their shape-stabilized PCM composition to improve their conductivity. The most complete study on those additives has been made by Zhang and al. [63]. They found that most efficient conducting material was ex-foliated graphite. The conductivity of their shape-stabilized PCM evolved from $0.150 \mathrm{~W} / \mathrm{m} . \mathrm{K}$ to $0.229 \mathrm{~W} / \mathrm{m} . \mathrm{K}$ by adding $10 \%$ weight graphite into the mixture. Zhang and al. [63] developed a model to predict the thermal conductivity of the material from its composition.

\subsection{Other containers}

Other containers can also be used for the integration of PCM in building walls. Ahmad et al. $[15,16]$ used PVC panels filled with PCM. Carbonari et al. [43] used sandwich panels with plastic rigid containers of PCM. Castell et al. [23] used CSM panels. Konuklu and Paksoy [31] tested aluminium foils to incorporate PCM in a multi-layers panel. Medina et al. [45], Voelker et al. [37], Zhang et al. [46] and Guceri and Faunce [64] filled tubes with PCM that was integrated in the wall. Pasupathy et al. [47] filled a steel container with PCM for being included in the roof slab. 


\section{Measurement of the thermal properties of a PCM and PCMIBW}

Arkar and al. [65] and Cho and Choi [66] showed that a perfect knowledge of the thermal properties of the PCM and the way those properties are measured, is necessary to correctly analyze a latent heat storage system. Tyagi and Buddha [8] warn the reader about data provided by the manufacturer, which could be erroneous (usually over optimistic).

Thus, measurement methods have been developed in order to get the thermodynamic characteristics of PCMs. Even if several measurement methods exist, the differential scanning calorimetry (DSC) is the most common one.

\subsection{DSC: Differential Scanning Calorimetry}

This measurement method has been initially developed to characterize the heat exchanges between some materials and their environment during transformations such polymerization or phase change of polymers. The name Differential Scanning Calorimetry is very explicit:

- Calorimetry: the calorimetry is the measurement of the quantity of heat which can be absorbed or released by a body subjected to a change of temperature. In our case, the heat transfer is due to conduction.

- Differential: the measurement setup is designed to have two different samples in identical conditions. The thermal reaction of the sample to characterize is obtained by comparison with the thermal reaction of the reference sample (which properties are known).

- Scanning: the thermal excitation is a ramp of temperature. The temperature rate has to be determined by the researcher. 
Two kinds of DSC setups exist. The power compensation DSC consists in two independent calorimeters. The heat flux DSC has got a Siamese structure: the two samples are connected to the same metal disc; the behavior difference of the samples submit to the same temperature excitation leads to a voltage difference between the samples; the absorbed heat in the PCM sample is deduced from the voltage.

The weight of DSC measurement sample is only a few grams. Thus, DSC provides information about the local properties of the material. It does not characterize the the thermal behavior of the bulk BIPCM and then this method is useful when the composite PCM characteristic size can be tested.

The Annex 17 of ECES (International Energy Agency) [67] observed the response of several samples with different masses, to a temperature scanning with different rates. The material of the sample did not suffer from super cooling. Results are shown on the figure 17. The equivalent heat capacity calculated using the DSC curves is clearly influenced by the sample mass and heating rate. The DSC is a complex system and the direct use of the measured curves is not physically correct because some heat transfer phenomena are omitted: the convection in the sample (i.e. capsule), the non uniformity of the temperature in the sample (conduction), the time needed to heat or cool the sample (inertia)...An inverse method based on this physical phenomena is necessary to qualitatively enhance the results of DSC.

The figure 18 from [39] shows the DSC curves obtained for a paraffin mixture. The heating and cooling curves are of course different and the melting and freezing temperatures are $13.6^{\circ} \mathrm{C}$ and $23.5^{\circ} \mathrm{C}$ respectively. The mixture phase change depends on the phase diagram but the DSC curves are 
not sufficient to get it. Further investigations are needed to calculate, from DSC, the physical characteristics needed to model the phase change of such PCM mixture.

\subsection{The T-history method}

The T-history method has been designed to test large samples. It also provides information about the thermal conductivity of the PCMIBW, and allows to test several samples at the same time.

The method is explained by Yinping and Al. [68]: samples of PCMIBW are put in different vertical tubes, a reference material is also put in a vertical tube. The temperature of the sample is measured with a thermocouple located at the center of the tube. At the beginning of the test, all the materials are in the liquid phase. The tubes are suddenly immersed into a controlled atmosphere (usually cold water), in which the temperature is regulated and is below the fusion temperature of the PCMIBW. The temperature inside each tube and in the controlled atmosphere is monitored; an example of the curve obtained is shown on the figure 19 .

A convective coefficient is deduced from the temperature curve of the reference material. Three steps appear in the temperature curve of the PCMIBWs: the cooling of the liquid phase, the solidification of the PCM, the cooling of the solid phase. The latent heat of the material and the heat capacity of its different phases are obtained after the calculation of the areas between the sample temperature curve and the atmosphere temperature curve $\left(A_{1}, A_{2}\right.$ and $\left.A_{3}\right)$ for each step. The thermal conductivity of the sample is obtained by using an inverse method on the total solidification time.

The method was improved by Marin et Al. [69] to obtain the heat capacity 
as a function of the temperature. Peck et Al. [70] proposed to lie the tubes horizontally in order to minimize disparities of the heat flux on their surface.

\subsection{The guarded hot-plate setup}

Darkwa et al. [71] used the guarded hot-plate to compare the storage performances of two different PCM wallboards. The setup contained a stack composed of a cold source, a hot source, a heat flux meter and the wallboard sample. The stack is isolated on every side. The figure 20 shows the setup. The specificities of the wall board sample are obtained by integration of the measured heat flux during the phase change.

Schossig et al. [61] also designed a guarded hot-plate type measurement setup. The stack was composed of the wall sample and one copper plate on each side.

\section{Experimental studies}

The table 3 summarizes the experimental studies concerning measurements held in a room with walls containing PCM . Most of these experiments were carried out in outdoor conditions with no internal gains due to occupation (i.e. real use of the building). The phase change temperature of the materials tested varies between $20^{\circ} \mathrm{C}$ and $30^{\circ} \mathrm{C}$ which is the usual thermal comfort zone of buildings. The PCM are mainly contained in plaster boards.

In the majority of the experimental studies, the measurements concern the air temperature in the test cell (usually one point) and, sometimes, the walls temperature. In all the cases, the major effect of PCMIBW is to reduce the temperature fluctuations with a more or less important time lag concerning the temperature maximum. There are few studies with heat flux 


\begin{tabular}{|c|c|c|c|c|c|}
\hline Ref. & Material & Container & Cell size & Number of cells & Conditions \\
\hline$[16]$ & PEG600 & PVC panel & $0.9 m \times 0.9 m \times 0.9 m$ & 2 & outdoor \\
\hline$[18]$ & butyl stearate & gypsum & $2.88 m \times 2.22 \mathrm{~m} \times 2.24 \mathrm{~m}$ & 1 & outdoor \\
\hline$[20]$ & butyl stearate palmitate;EMEREST2325 & gypsum & $2.27 m \times 2.29 m \times 2.45 m$ & 2 & laboratory \\
\hline$[26]$ & MICRONAL26 & gypsum & $2.4 m \times 2.4 m \times 2.4 m$ & 2 & outdoor \\
\hline$[43]$ & eutectic salt & sandwich panel & $4.37 m \times 3.39 m \times 2.7 m$ & 1 & laboratory \\
\hline$[23]$ & $\mathrm{RT} 27 ; \mathrm{SP} 25 \mathrm{~A} 8$ & CSM panel & $2.4 m \times 2.4 m \times 2.4 m$ & 2 & outdoor \\
\hline$[24]$ & MICRONAL26; RT27 & & $2.4 m \times 2.4 m \times 2.4 m$ & 2 & outdoor \\
\hline$[27]$ & RT20 & gypsum & $0.7 m \times 0.7 m \times 0.7 m$ & 3 & laboratory \\
\hline$[72]$ & RT20 & gypsum & $0.7 m \times 0.7 m \times 0.7 m$ & 3 & laboratory \\
\hline$[31]$ & PCM5001; PCM5008 & aluminium foils & $2.7 m \times 2 m \times 1.5 m$ & 3 & outdoor \\
\hline$[38]$ & $\mathrm{U} 4$ & ENERGAIN & $3.1 m \times 3.1 m \times 2.5 m$ & 1 & laboratory \\
\hline$[39]$ & $\mathrm{U} 4$ & ENERGAIN & $3.1 m \times 3.1 m \times 2.5 m$ & 1 & laboratory \\
\hline$[40]$ & $\mathrm{U} 4$ & ENERGAIN & $0.5 m \times 0.5 m \times 0.5 m$ & 2 & laboratory \\
\hline$[53]$ & paraffin & shape-stabilized & $0.575 m \times 0.453 m \times 0.463 m$ & 1 & outdoor \\
\hline$[54]$ & paraffin & shape-stabilized & $3 m \times 2 m \times 2 m$ & 1 & outdoor \\
\hline$[41]$ & U4 & ENERGAIN & $4 m \times 3 m \times 2.5 m$ & 1 & laboratory \\
\hline$[45]$ & $\mathrm{U} 1$ & tube & $1.83 m \times 1.83 m \times 1.22 m$ & 2 & outdoor \\
\hline$[47]$ & $\mathrm{U} 2$ & steel & $1.22 m \times 1.22 m \times 2.44 m$ & 2 & outdoor \\
\hline$[21]$ & EMEREST2325 & gypsum & $2.27 m \times 2.29 m \times 2.45 m$ & 2 & laboratory \\
\hline$[61]$ & & gypsum & room of a building & 2 & outdoor \\
\hline$[36]$ & capric-lauric non eutectic & gypsum & $5 m \times 3.3 m \times 2.8 m$ & 1 & outdoor \\
\hline$[37]$ & $\mathrm{U} 3 ; \mathrm{CaCl} 2.6 \mathrm{H} 20$ & gypsum; tube & $2.95 m \times 4.43 m \times 2 m$ & 2 & outdoor \\
\hline$[46]$ & $\mathrm{U} 1$ & tube & $1.83 m \times 1.83 m \times 1.22 m$ & 2 & outdoor \\
\hline$[56]$ & paraffin & shape-stabilized & $3 m \times 2 m \times 2 m$ & 1 & outdoor \\
\hline
\end{tabular}


measurements whereas it is an interesting way to calculate the thermal energy stored/release. On the whole, There is a lack of indicators allowing to evaluate the real effectiveness of the solutions tested.

The thermal comfort of occupants is driven in particular by the air temperature (convective heat transfer) and the surface temperature using the mean radiant temperature (radiative heat transfer). A special attention must be paid to these two parameters to really assess the effect of PCM on thermal comfort.

Concerning the energy, Castell et al. [23] measured a reduction of about $15 \%$ of electricity consumption during summer 2008. A more systematic study of energy reduction coupled with life cycle analysis is necessary to really assess the performance of PCMIBW.

\section{Numerical studies}

The phase change can be taken into account in the heat equation using either the effective heat capacity method or the enthalpy method. These two methods have been extensively studied in the literature, for example: [73-75] for the effective heat capacity method and [76-78] for the enthalpy formulation method. The two methods have the advantages of allowing to use one formulation of the heat equation for the entire domain and of avoiding to solve the melting front position.

The numerical studies involving PCM integrated in building walls can be roughly categorized as follow:

- unidirectional heat equation in a single wall: $[13,15,32,38,42,47,71$, 79-86]. 
- two dimensional heat equation in a single wall: [17, 43, 87].

- unidirectional heat equation in the wall, energy balance in a room: $[40,53,88-96]$.

- two or three dimensional heat equation in the wall, energy balance in a room: $[16,97]$.

Most of the studies concerning unidirectional heat equation in a building wall with PCM deals with the problem of PCM optimization: phase change temperature, position of the PCM, thickness. One of the most important feature is the thickness of the PCM wall: the more the wall is thick, the more the price of the construction is high. Of course, when the thickness is large, the time needed for the heat to penetrate the PCM becomes larger than $12 \mathrm{~h}$ and the storage process cannot be complete during a day [13]. This optimal thickness depends on the diffusivity of the medium and then must be held for each PCMIBW.

The unidirectional conductive heat transfer in walls is a common assumption in building simulation. In low energy building, this assumption is no more realistic and then attention must be paid in future studies concerning this assumption especially for thermal bridges reduction.

The heat transfer between the PCM wall and the air is due to convection. For external walls surface, the convective heat transfer is driven by forced convection, but as the walls are insulated, this transfer process is not prevalent. The convective heat transfer between the internal face of the wall and the indoor air is important to evaluate the store/release process in PCM. Liu and Hawbi [41] found that the correlation used to evaluate the convective 
heat transfer for ordinary walls underestimate this coefficient for PCM wall (by a factor of 2 in their experiment). This is a very important problem because there is a lack of knowledge concerning the convective heat transfer with PCM walls whereas numerical simulations need the convective heat transfer value!

Most of the studies deal with non-occupied rooms. Of course, the evaluation of air temperature in a building is clearly affected by internal heat loads. One way to evaluate the optimum phase change temperature is to calculate the thermal evolution of a building without PCM and calculate the mean surface temperature of the walls for the storage period. This optimization can only be done if internal loads due to occupation are taken into account with realistic scenario.

\section{Conclusions}

This paper is the state of the art of phase change material integrated in building walls. All of the PCM reviewed have a good potential for reducing cooling loads by enhancing the storage capacity of the building envelop. However, this storage capacity can be enhanced with an increase of the PCMIBW thermal conductivity.

From a practical point of view, a more systematic evaluation of the various PCM integrated in the building structure is needed, in particular in real use condition. Such analysis can be numerical but attention must be paid to numerical modeling assumptions: convective heat transfer coefficient, use of the phase diagram... .Moreover, there is a lack of clear indicator to effectively assess the PCMIBW. 


\section{References}

[1] Climate plan 2004: let's act together to challenge of climate change, Tech. rep., French Ministry of Ecology and Sustainable Developpment (2004).

[2] I. Dincer, M. Rosen, Thermal Energy Storage - Systems and Applications, Jhon Wiley and Sons, 2002.

[3] R. Baetens, B. P. Jelle, A. Gustavsen, Phase change materials for building applications: A state-of-the-art review, Energy and Buildings In Press, Accepted Manuscript (2010) -.

[4] M. M. Farid, A. M. Khudhair, S. A. K. Razack, S. Al-Hallaj, A review on phase change energy storage: materials and applications, Energy Conversion and Management 45 (9-10) (2004) 1597 - 1615.

[5] A. Pasupathy, R. Velraj, R. Seeniraj, Phase change material-based building architecture for thermal management in residential and commercial establishments, Renewable and Sustainable Energy Reviews $12(1)(2008) 39-64$.

[6] A. Sharma, V. Tyagi, C. Chen, D. Buddhi, Review on thermal energy storage with phase change materials and applications, Renewable and Sustainable Energy Reviews 13 (2) (2009) 318 - 345.

[7] U. Stritih, Heat transfer enhancement in latent heat thermal storage system for buildings, Energy and Buildings 35 (11) (2003) 1097 - 1104. 
[8] V. V. Tyagi, D. Buddhi, Pcm thermal storage in buildings: A state of art, Renewable and Sustainable Energy Reviews 11 (6) (2007) 1146 1166.

[9] B. Zalba, J. M. Marn, L. F. Cabeza, H. Mehling, Free-cooling of buildings with phase change materials, International Journal of Refrigeration 27 (8) (2004) $839-849$.

[10] Y. Zhang, G. Zhou, K. Lin, Q. Zhang, H. Di, Application of latent heat thermal energy storage in buildings: State-of-the-art and outlook, Building and Environment 42 (6) (2007) 2197 - 2209.

[11] N. Zhu, Z. Ma, S. Wang, Dynamic characteristics and energy performance of buildings using phase change materials: A review, Energy Conversion and Management 50 (12) (2009) 3169 - 3181.

[12] K. Peippo, P. Kauranen, P. Lund, A multicomponent pcm wall optimized for passive solar heating, Energy and Buildings 17 (4) (1991) 259 -270 .

[13] B. He, V. Martin, F. Setterwall, Phase transition temperature ranges and storage density of paraffin wax phase change materials, Energy 29 (11) (2004) $1785-1804$.

[14] M. Ahmad, A. Bontemps, H. Salle, D. Quenard, Experimental investigation and computer simulation of thermal behaviour of wallboards containing a phase change material, Energy and Buildings 38 (4) (2006) $357-366$. 
[15] M. Ahmad, A. Bontemps, H. Salle, D. Quenard, Thermal testing and numerical simulation of a prototype cell using light wallboards coupling vacuum isolation panels and phase change material, Energy and Buildings 38 (6) (2006) $673-681$.

[16] E. M. Alawadhi, Thermal analysis of a building brick containing phase change material, Energy and Buildings 40 (3) (2008) 351 - 357.

[17] A. K. Athienitis, C. Liu, D. Hawes, D. Banu, D. Feldman, Investigation of the thermal performance of a passive solar test-room with wall latent heat storage, Building and Environment 32 (5) (1997) 405 - 410.

[18] T. Lee, D. W. Hawes, D. Banu, D. Feldman, Control aspects of latent heat storage and recovery in concrete, Solar Energy Materials and Solar Cells 62 (3) (2000) $217-237$.

[19] D. Banu, D. Feldman, D. Hawes, Evaluation of thermal storage as latent heat in phase change material wallboard by differential scanning calorimetry and large scale thermal testing, Thermochimica Acta 317 (1) (1998) $39-45$.

[20] S. Scalat, D. Banu, D. Hawes, J. Parish, F. Haghighata, D. Feldman, Full scale thermal testing of latent heat storage in wallboard, Solar Energy Materials and Solar Cells 44 (1) (1996) 49 - 61.

[21] A. M. Borreguero, M. Carmona, M. L. Sanchez, J. L. Valverde, J. F. Rodriguez, Improvement of the thermal behaviour of gypsum blocks by the incorporation of microcapsules containing pcms obtained by suspen- 
sion polymerization with an optimal core/coating mass ratio, Applied Thermal Engineering 30 (10) (2010) 1164 - 1169.

[22] A. Castell, I. Martorell, M. Medrano, G. Prez, L. Cabeza, Experimental study of using pcm in brick constructive solutions for passive cooling, Energy and Buildings 42 (4) (2010) 534 - 540.

[23] C. Castellón, A. Castell, M. Medrano, I. Martorell, L. F. Cabeza, Experimental study of pcm inclusion in different building envelopes, Journal of Solar Energy Engineering 131 (4) (2009) 041006.

[24] A. C. Evers, M. A. Medina, Y. Fang, Evaluation of the thermal performance of frame walls enhanced with paraffin and hydrated salt phase change materials using a dynamic wall simulator, Building and Environment 45 (8) (2010) $1762-1768$.

[25] L. F. Cabeza, C. Castelln, M. Nogus, M. Medrano, R. Leppers, O. Zubillaga, Use of microencapsulated pcm in concrete walls for energy savings, Energy and Buildings 39 (2) (2007) 113 - 119.

[26] X. Fang, Z. Zhang, A novel montmorillonite-based composite phase change material and its applications in thermal storage building materials, Energy and Buildings 38 (4) (2006) 377 - 380.

[27] D. Feldman, D. Banu, D. W. Hawes, Development and application of organic phase change mixtures in thermal storage gypsum wallboard, Solar Energy Materials and Solar Cells 36 (2) (1995) 147 - 157.

[28] M. Huang, P. Eames, N. Hewitt, The application of a validated numerical model to predict the energy conservation potential of using phase 
change materials in the fabric of a building, Solar Energy Materials and Solar Cells 90 (13) (2006) $1951-1960$.

[29] A. Karaipekli, A. SarI, Capric-myristic acid/expanded perlite composite as form-stable phase change material for latent heat thermal energy storage, Renewable Energy 33 (12) (2008) 2599 - 2605.

[30] Y. Konuklu, H. O. Paksoy, Phase change material sandwich panels for managing solar gain in buildings, Journal of Solar Energy Engineering 131 (4) (2009) 041012.

[31] M. Koschenz, B. Lehmann, Development of a thermally activated ceiling panel with pcm for application in lightweight and retrofitted buildings, Energy and Buildings 36 (6) (2004) 567 - 578.

[32] C. ming Lai, R. Chen, C.-Y. Lin, Heat transfer and thermal storage behaviour of gypsum boards incorporating micro-encapsulated pcm, Energy and Buildings In Press, Corrected Proof (2010)-.

[33] H. Li, X. Liu, G. Fang, Preparation and characteristics of nnonadecane/cement composites as thermal energy storage materials in buildings, Energy and Buildings In Press, Accepted Manuscript (2010)

[34] A. Sari, A. Karaipekli, K. Kaygusuz, Capric acid and stearic acid mixture impregnated with gypsum wallboard for low-temperature latent heat thermal energy storage, International Journal of Energy Research 32 (2) (2008) 154-160. 
[35] L. Shilei, F. Guohui, Z. Neng, D. Li, Experimental study and evaluation of latent heat storage in phase change materials wallboards, Energy and Buildings 39 (10) (2007) 1088 - 1091.

[36] C. Voelker, O. Kornadt, M. Ostry, Temperature reduction due to the application of phase change materials, Energy and Buildings 40 (5) (2008) $937-944$.

[37] F. Kuznik, J. Virgone, J. Noel, Optimization of a phase change material wallboard for building use, Applied Thermal Engineering 28 (11-12) (2008) $1291-1298$.

[38] F. Kuznik, J. Virgone, J.-J. Roux, Energetic efficiency of room wall containing pcm wallboard: A full-scale experimental investigation, Energy and Buildings 40 (2) (2008) $148-156$.

[39] F. Kuznik, J. Virgone, Experimental assessment of a phase change material for wall building use, Applied Energy 86 (10) (2009) 2038 - 2046.

[40] F. Kuznik, J. Virgone, Experimental investigation of wallboard containing phase change material: Data for validation of numerical modeling, Energy and Buildings 41 (5) (2009) $561-570$.

[41] H. Liu, H. B. Awbi, Performance of phase change material boards under natural convection, Building and Environment 44 (9) (2009) 1788 - 1793.

[42] H. Weinlder, A. Beck, J. Fricke, Pcm-facade-panel for daylighting and room heating, Solar Energy 78 (2) (2005) 177 - 186, iSES Solar World Congress 2003. 
[43] A. Carbonari, M. D. Grassi, C. D. Perna, P. Principi, Numerical and experimental analyses of pcm containing sandwich panels for prefabricated walls, Energy and Buildings 38 (5) (2006) 472 - 483.

[44] M. Hadjieva, R. Stoykov, T. Filipova, Composite salt-hydrate concrete system for building energy storage, Renewable Energy 19 (1-2) (2000) $111-115$.

[45] M. A. Medina, J. B. King, M. Zhang, On the heat transfer rate reduction of structural insulated panels (sips) outfitted with phase change materials (pcms), Energy 33 (4) (2008) $667-678$.

[46] M. Zhang, M. A. Medina, J. B. King, Development of a thermally enhanced frame wall with phase-change materials for on-peak air conditioning demand reduction and energy savings in residential buildings, International Journal of Energy Research 29 (9) (2005) 795-809.

[47] A. Pasupathy, L. Athanasius, R. Velraj, R. Seeniraj, Experimental investigation and numerical simulation analysis on the thermal performance of a building roof incorporating phase change material $(\mathrm{pcm})$ for thermal management, Applied Thermal Engineering 28 (5-6) (2008) 556 565.

[48] A. M. Khudhair, M. M. Farid, A review on energy conservation in building applications with thermal storage by latent heat using phase change materials, Energy Conversion and Management 45 (2) (2004) 263 - 275.

[49] M. Xiao, B. Feng, K. Gong, Preparation and performance of shape sta- 
bilizes phase change thermal storage materials with high thermal conductivity, Energy conversion and management 43 (2002) 103-108.

[50] D. W. Hawes, D. Feldman, D. Banu, Latent heat storage in building materials, Energy and Buildings 20 (1) (1993) 77 - 86.

[51] D. Feldman, D. Banu, D. Hawes, E. Ghanbari, Obtaining an energy storing building material by direct incorporation of an organic phase change material in gypsum wallboard, Solar Energy Materials 22 (2-3) (1991) $231-242$.

[52] D. Feldman, D. Banu, Dsc analysis for the evaluation of an energy storing wallboard, Thermochimica Acta 272 (1996) 243 - 251, advances in International Thermal Sciences: Environment, Polymers, Energy and Techniques.

[53] J. Li, P. Xue, H. He, W. Ding, J. Han, Preparation and application effects of a novel form-stable phase change material as the thermal storage layer of an electric floor heating system, Energy and Buildings 41 (8) (2009) $871-880$.

[54] K. Lin, Y. Zhang, X. Xu, H. Di, R. Yang, P. Qin, Experimental study of under-floor electric heating system with shape-stabilized pcm plates, Energy and Buildings 37 (3) (2005) 215 - 220.

[55] X. Xu, Y. Zhang, K. Lin, H. Di, R. Yang, Modeling and simulation on the thermal performance of shape-stabilized phase change material floor used in passive solar buildings, Energy and Buildings 37 (10) (2005) $1084-1091$. 
[56] Y. Zhang, K. Lin, R. Yang, H. Di, Y. Jiang, Preparation, thermal performance and application of shape-stabilized pcm in energy efficient buildings, Energy and Buildings 38 (10) (2006) 1262 - 1269.

[57] M. Hawlder, M. Uddin, M. M. Khin, Microencapsulated pcm thermalenergy storage system, Applied Energy 74 (2003) 195-202.

[58] X.-X. Zhang, Y.-F. Fan, X.-M. Tao, K.-L. Yick, Crystallization and prevention of supercooling of microencapsulated n-alkanes, Journal of Collode and Interface Science 281 (2005) 299-306.

[59] N. Sarier, E. Onder, The manufacture of microencapsulated phase change materials suitable for the design of thermally enhanced fabrics, Thermochimica Acta 452 (2007) 149-160.

[60] Y. Yamagishi, T. Sugeno, T. Ishige, H. Takeuchi, A. Pyatenko, An evaluation of microencapsulated pcm for use in cold energy transportation medium, in: Energy Conversion Engineering Conference, 1996. IECEC 96. Proceedings of the 31st Intersociety, P2077, 1996.

[61] P. Schossig, H.-M. Henning, S. Gschwander, T. Haussmann, Microencapsulated phase-change materials integrated into construction materials, Solar Energy Materials and Solar Cells 89 (2-3) (2005) 297 306.

[62] A. Sari, Form-stable paraffin/high density polytehylene composites as a solid-liquid phase change material for thermal energy storage: preparation and thermal properties, Energy conversiona and management 45 (2004) 2033-2042. 
[63] Y. Zhang, J. Ding, X. Wang, R. Yang, K. Lin, Influence of additives on thermal conductivity od shape-stabilized plase change material, Solar energy materials and solar cells 90 (2006) 1692-1702.

[64] S. Guceri, S. Faunce, Modeling of a thermal wall panel using phase change materials, Energy 4 (4) (1979) 695 - 699.

[65] C. Arkar, S. Medved, Influence of accuracy of thermal property data of phase change material on the result of a numerical model of packed bed latent heat storage with spheres, Thermochimica Acta 438 (2005) $192-201$.

[66] K. Cho, S. Choi, Thermal caracteristics of paraffin in a spherical capsule during freezing and melting process, International Journal of Heat and Mass Transfert 43 (2000) 3183-3196.

[67] A. 17-ECES-IEA, Advanced thermal energy storage through phase change materials and chemical reactions feasibility studies and demonstration projects, Tech. rep., International Energy Agency Implementing Agreement on Energy Conservation through Energy Storage (2005).

[68] Z. Yinping, J. Yi, A simple method, the t-history method, of determining the heat of fusion, specific heat and thermal conductivity of phase change material, Measurement Science and Technology 10 (1999) 201205.

[69] J. Marin, B. Zalba, L. Cabeza, H. Mehling, Determination of enthalpytemperature curves of phase change materials with the temperature his- 
tory method: improvement to temperature dependent properties, Measurement Science and Technology 14 (2003) 184-189.

[70] J. Peck, J.-J. Kim, C. Kang, H. Hong, A study of accurate latent heat measurement for a pcm with a low melting temperature using t-history method, International Journal of Refrigeration 29 (2006) 1225-1232.

[71] K. Darkwa, J.-S. Kim, Dynamics of energy storage in phase change drywall systems, International Journal of Energy Research 29 (4) (2005) 335-343.

[72] X. Fang, Z. Zhang, Z. Chen, Study on preparation of montmorillonitebased composite phase change materials and their applications in thermal storage building materials, Energy Conversion and Management 49 (4) (2008) $718-723$.

[73] L. E. Goodrich, Efficient numerical technique for one-dimensional thermal problems with phase change, International Journal of Heat and Mass Transfer 21 (5) (1978) $615-621$.

[74] G. Comini, S. D. Guidice, R. W. Lewis, O. C. Zienkiewicz, Finite element solution of non-linear heat conduction problems with special reference to phase change, International Journal for Numerical Methods in Engineering 8 (3) (1974) 613-624.

[75] Y. Minwu, A. Chait, An alternative formulation of the apparent heat capacity method for phase-change problems, J Numerical Heat Transfer, Part B: Fundamentals: An International Journal of Computation and Methodology 24 (3) (1993) 279-300. 
[76] S. Kakac, Y. Yener, Heat Conduction, 4th Edition, Taylor \& Francis, 2008.

[77] V. Voller, M. Cross, Accurate solutions of moving boundary problems using the enthalpy method, International Journal of Heat and Mass Transfer 24 (3) (1981) $545-556$.

[78] A. Date, A strong enthalpy formulation for the stefan problem, International Journal of Heat and Mass Transfer 34 (9) (1991) 2231 - 2235.

[79] K. Darkwa, Quasi-isotropic laminated phase-change material system, Applied Energy 84 (6) (2007) 599 - 607.

[80] K. Darkwa, J. S. Kim, Thermal analysis of composite phase change drywall systems, Journal of Solar Energy Engineering 127 (3) (2005) $352-356$.

[81] C. Halford, R. Boehm, Modeling of phase change material peak load shifting, Energy and Buildings 39 (3) (2007) 298 - 305.

[82] J.-S. Kim, K. Darkwa, Simulation of an integrated pcm-wallboard system, International Journal of Energy Research 27 (3) (2003) 215-223.

[83] F. Mathieu-Potvin, L. Gosselin, Thermal shielding of multilayer walls with phase change materials under different transient boundary conditions, International Journal of Thermal Sciences 48 (9) (2009) 1707 1717.

[84] Y. Zhang, K. Lin, Y. Jiang, G. Zhou, Thermal storage and nonlinear 
heat-transfer characteristics of pcm wallboard, Energy and Buildings 40 (9) (2008) 1771 - 1779.

[85] S. Kaushik, M. Sodha, S. Bhardwaj, N. Kaushik, Periodic heat transfer and load levelling of heat flux through a pccm thermal storage wall/roof in an air-conditioned building, Building and Environment 16 (2) (1981) $99-107$.

[86] G. Zhou, Y. Yang, X. Wang, J. Cheng, Thermal characteristics of shapestabilized phase change material wallboard with periodical outside temperature waves, Applied Energy In Press, Corrected Proof (2010) -.

[87] K. Darkwa, Evaluation of regenerative phase change drywalls: lowenergy buildings application, International Journal of Energy Research 23 (14) (1999) 1205-1212.

[88] C. Chen, H. Guo, Y. Liu, H. Yue, C. Wang, A new kind of phase change material (pcm) for energy-storing wallboard, Energy and Buildings 40 (5) (2008) $882-890$.

[89] K. Darkwa, P. O'Callaghan, Simulation of phase change drywalls in a passive solar building, Applied Thermal Engineering 26 (8-9) (2006) 853 -858 .

[90] D. Heim, Isothermal storage of solar energy in building construction, Renewable Energy 35 (4) (2010) 788 - 796.

[91] M. Ibanez, A. Lazaro, B. Zalba, L. F. Cabeza, An approach to the simulation of pcms in building applications using trnsys, Applied Thermal Engineering 25 (11-12) (2005) 1796 - 1807. 
[92] F. Kuznik, J. Virgone, K. Johannes, Development and validation of a new trnsys type for the simulation of external building walls containing pcm, Energy and Buildings 42 (7) (2010) $1004-1009$.

[93] D. A. Neeper, Thermal dynamics of wallboard with latent heat storage, Solar Energy 68 (5) (2000) $393-403$.

[94] G. Zhou, Y. Zhang, X. Wang, K. Lin, W. Xiao, An assessment of mixed type pcm-gypsum and shape-stabilized pcm plates in a building for passive solar heating, Solar Energy 81 (11) (2007) 1351 - 1360.

[95] G. Zhou, Y. Yang, X. Wang, S. Zhou, Numerical analysis of effect of shape-stabilized phase change material plates in a building combined with night ventilation, Applied Energy 86 (1) (2009) 52 - 59.

[96] S. Chandra, R. Kumar, S. Kaushik, S. Kaul, Thermal performance of a non-air-conditioned building with pccm thermal storage wall, Energy Conversion and Management 25 (1) (1985) $15-20$.

[97] S. Mozhevelov, G. Ziskind, R. Letan, Temperature moderation in a real-size room by pcm-based units, Journal of Solar Energy Engineering 128 (2) (2006) 178-188. 


\section{List of Figures}

1 Evolution of the number of publications since 1979. . . . . . . 46

2 Distribution of the publications per journal. . . . . . . . . . . 47

3 Number of publications per country. . . . . . . . . . . . . . 48

4 A schematic of heat transfers in a building. . . . . . . . . . . 49

5 A schematic of PCMIBW in a house with solar gain. . . . . . 50

6 Phase diagram. . . . . . . . . . . . . . . . . 51

7 Equilibrium areas of the liquid and solid phases at the atmospheric pressure. . . . . . . . . . . . . . 52

8 Time evolution of the temperature and heat flux during the solidification of a pure body submitted to a temperature step $\Delta T \ldots \ldots \ldots \ldots \ldots \ldots \ldots$

9 Heat flux profile of a temperature scanning response. . . . . . 54

10 Supercooling effect. . . . . . . . . . . . . . . . . 55

11 Binary phase diagram-Isomorphous system. . . . . . . . . 56

12 Binary phase diagram-Azeotropic point. . . . . . . . . . 57

13 Binary phase diagram-Eutectic point. . . . . . . . . . . 58

14 The liquid-solid phase diagram of binary mixtures system of $\mathrm{C}_{14} \mathrm{H}_{30}$ and $\mathrm{C}_{16} \mathrm{H}_{34}$ from [14]. . . . . . . . . . . . 59

15 SEM photography of a concrete wall containing micro-encapsulated PCM, from Schossig and al. [61]. . . . . . . . . . . . 60

16 Photos of the shape-stabilized PCM: a) the PCM plate b) SEM picture from Zhou and al. [94]. . . . . . . . . . . . . 61

17 Temperature scanning responses depending on sample mass and heating rate from [67]. . . . . . . . . . . . . . 62

18 Differential scanning calorimeter melting and freezing curves for the composite PCM from [39]. . . . . . . . . . . . . . . 63

19 T-history experimental setup and T-history temperature curves. 64

20 The measurement setup form de Darkwa et al. [71] . . . . . . . 65 


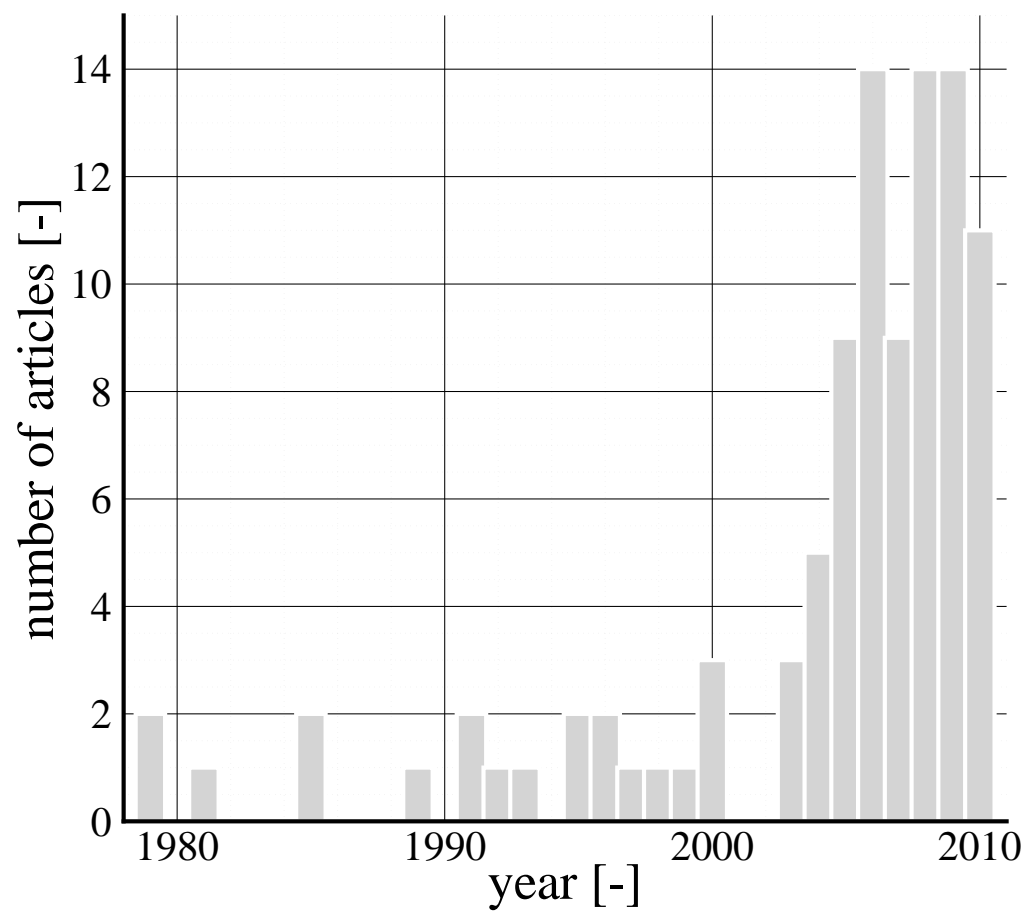

Figure 1: Evolution of the number of publications since 1979. 


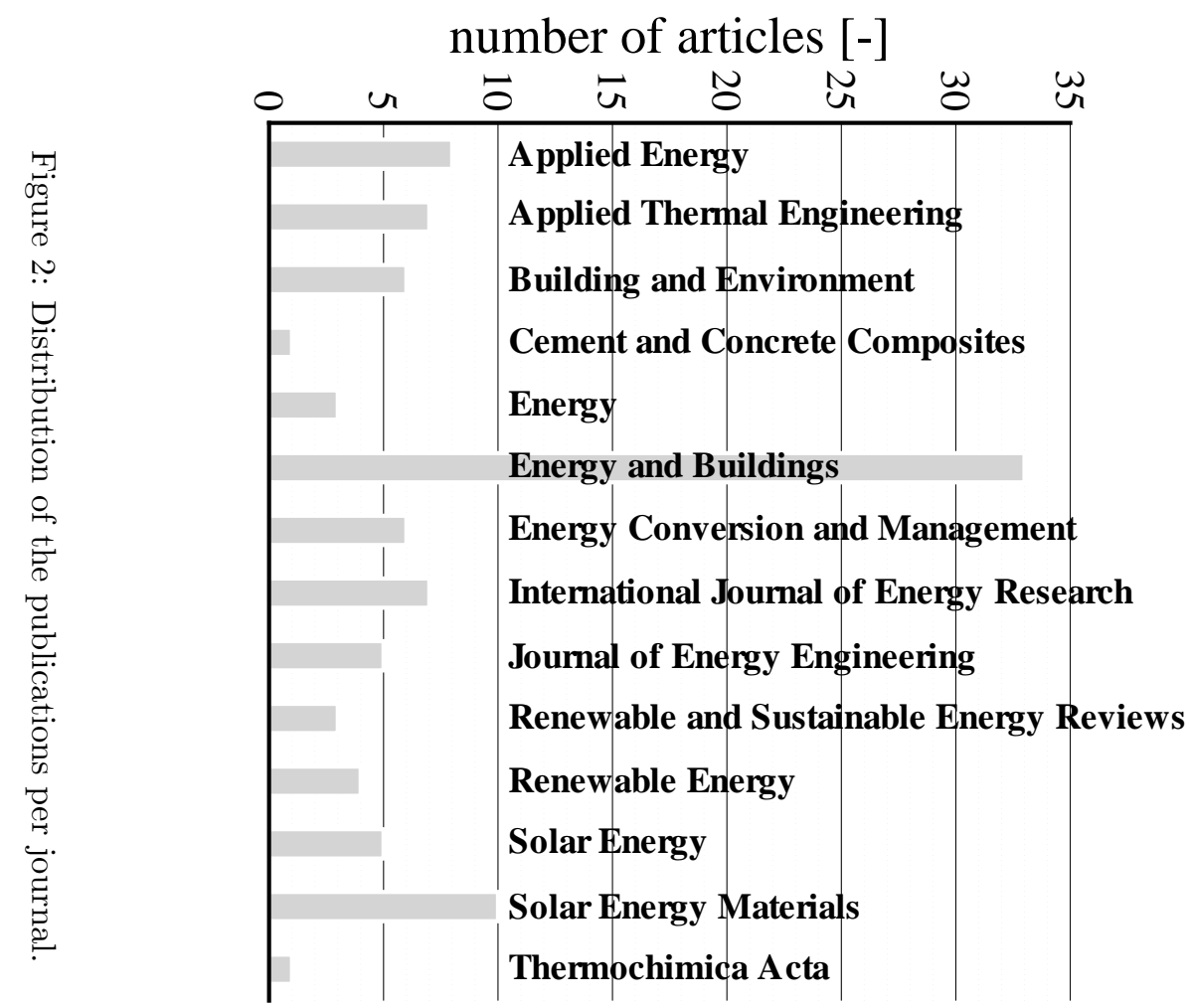




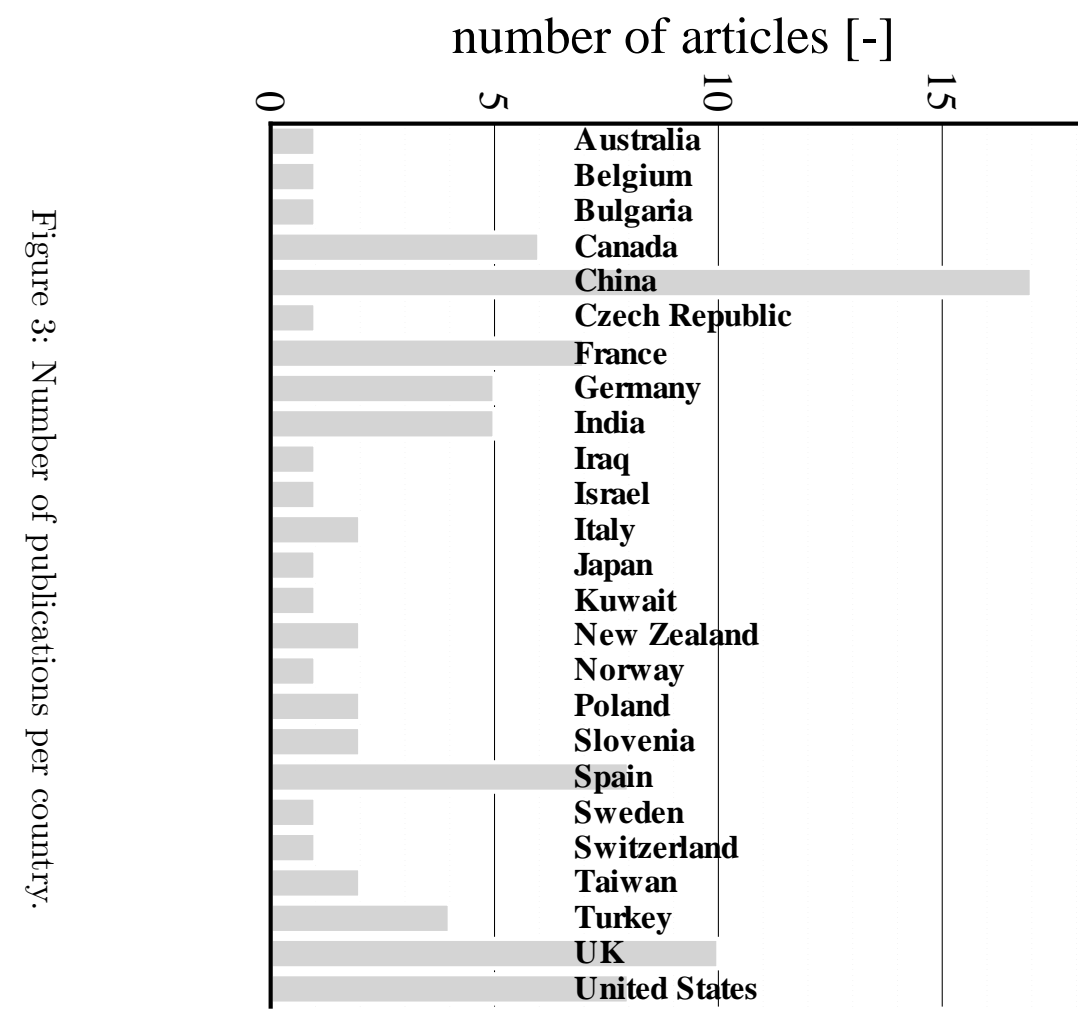




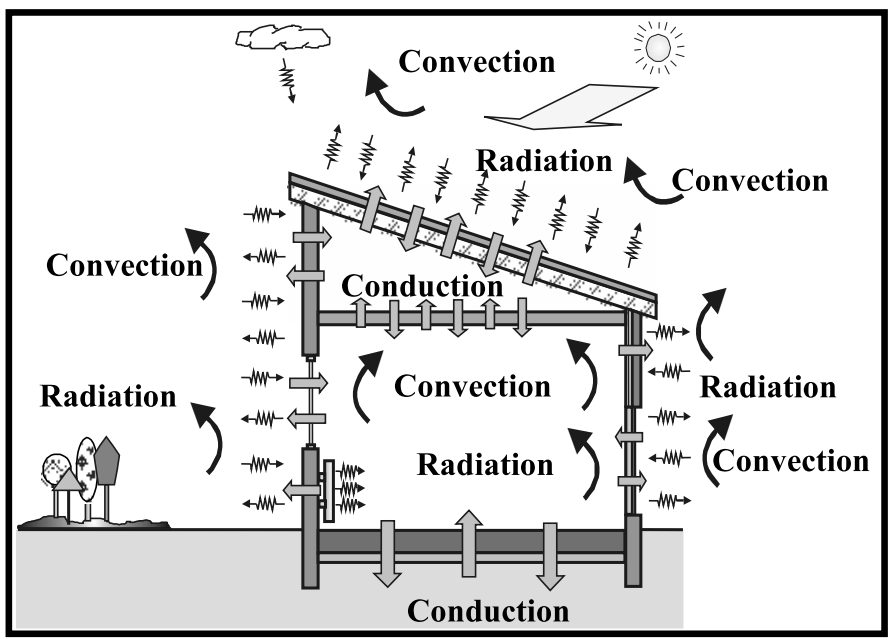

Figure 4: A schematic of heat transfers in a building. 


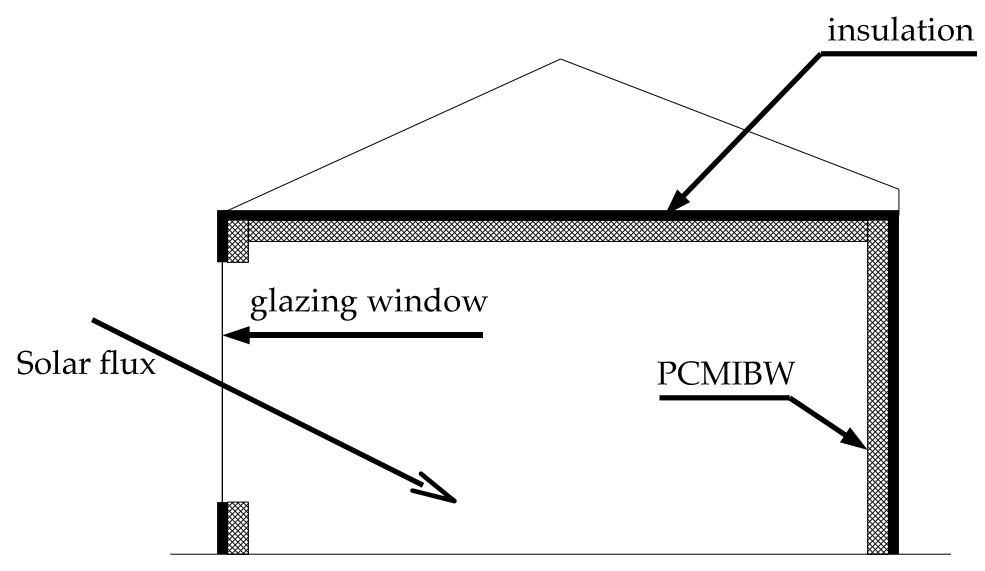

Figure 5: A schematic of PCMIBW in a house with solar gain. 


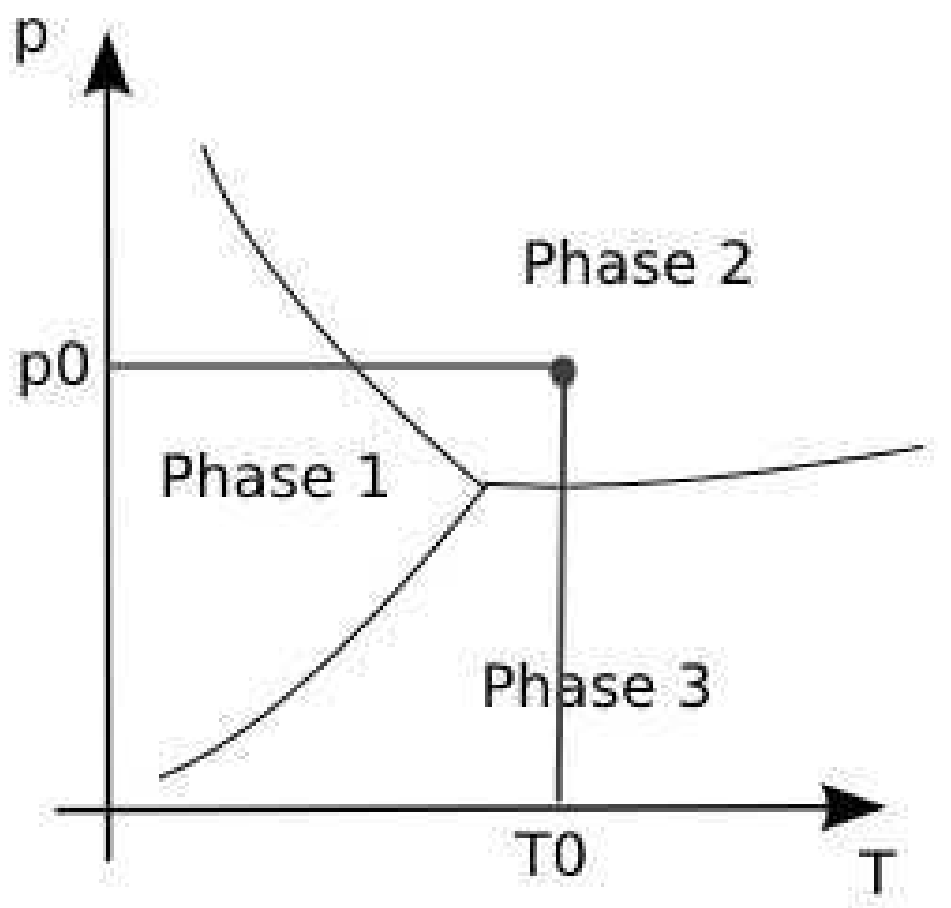

Figure 6: Phase diagram. 


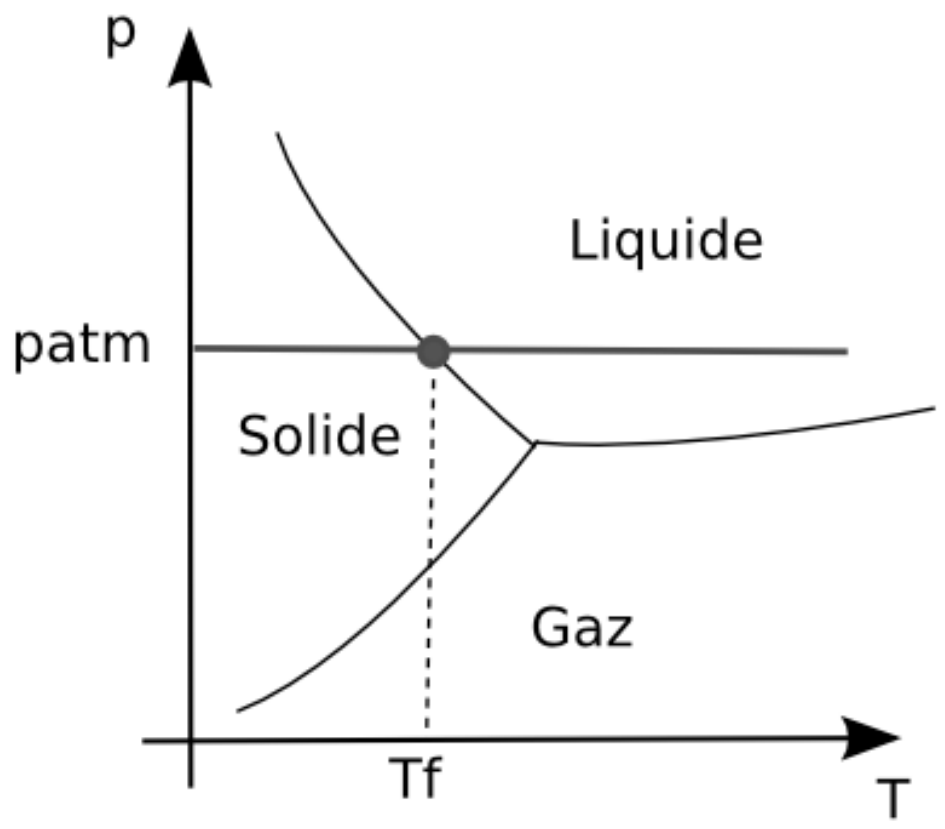

Figure 7: Equilibrium areas of the liquid and solid phases at the atmospheric pressure. 

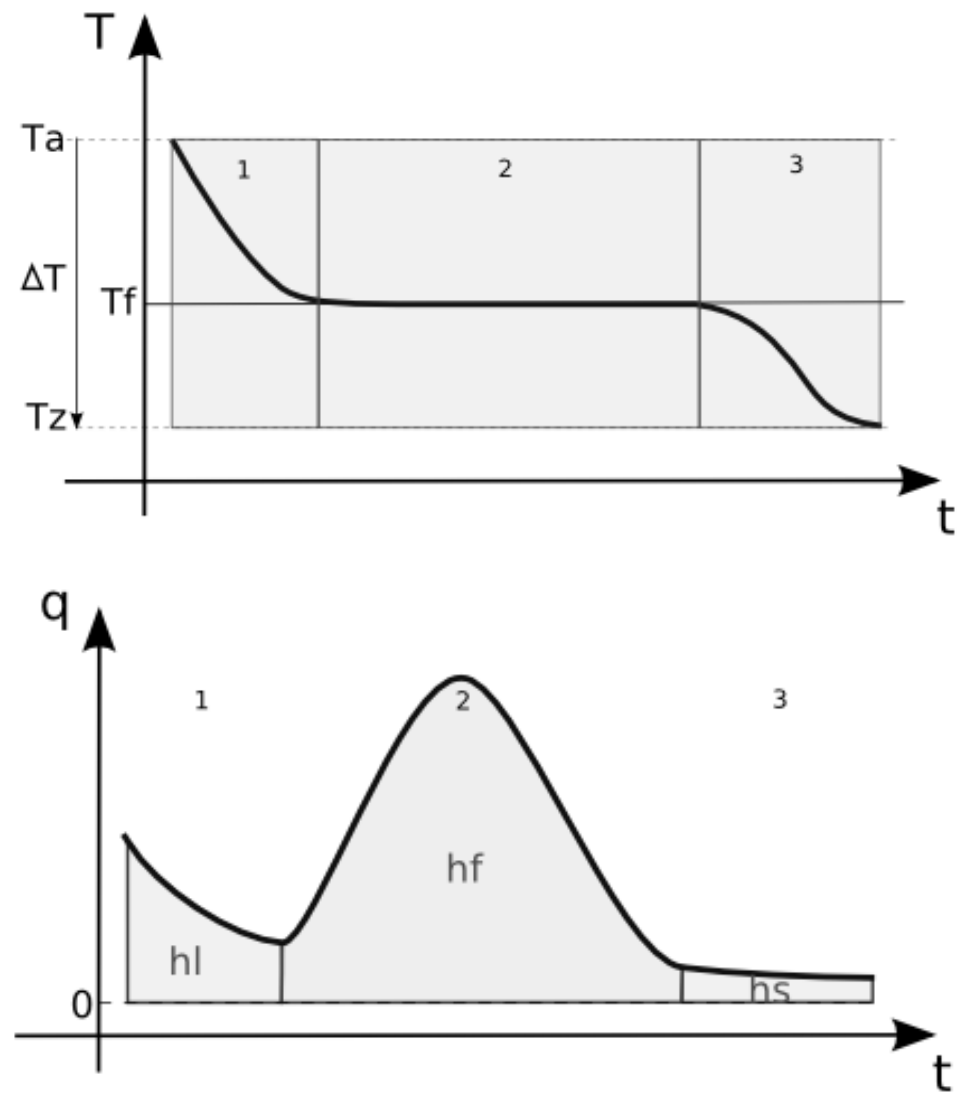

Figure 8: Time evolution of the temperature and heat flux during the solidification of a pure body submitted to a temperature step $\Delta T$. 


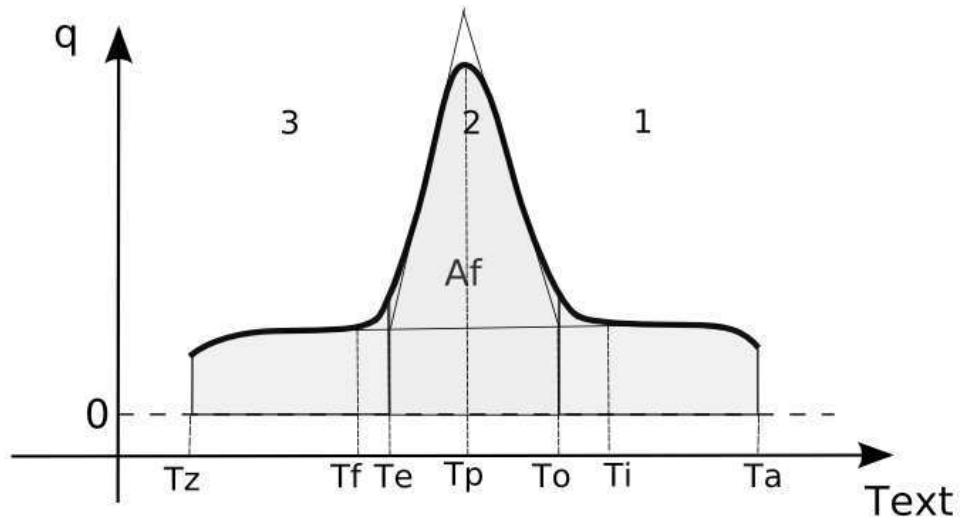

Figure 9: Heat flux profile of a temperature scanning response. 


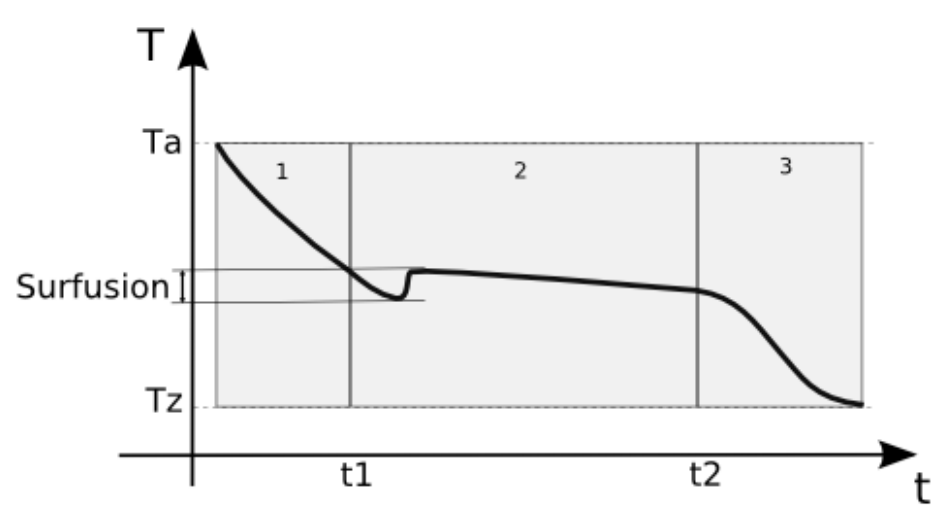

Figure 10: Supercooling effect. 


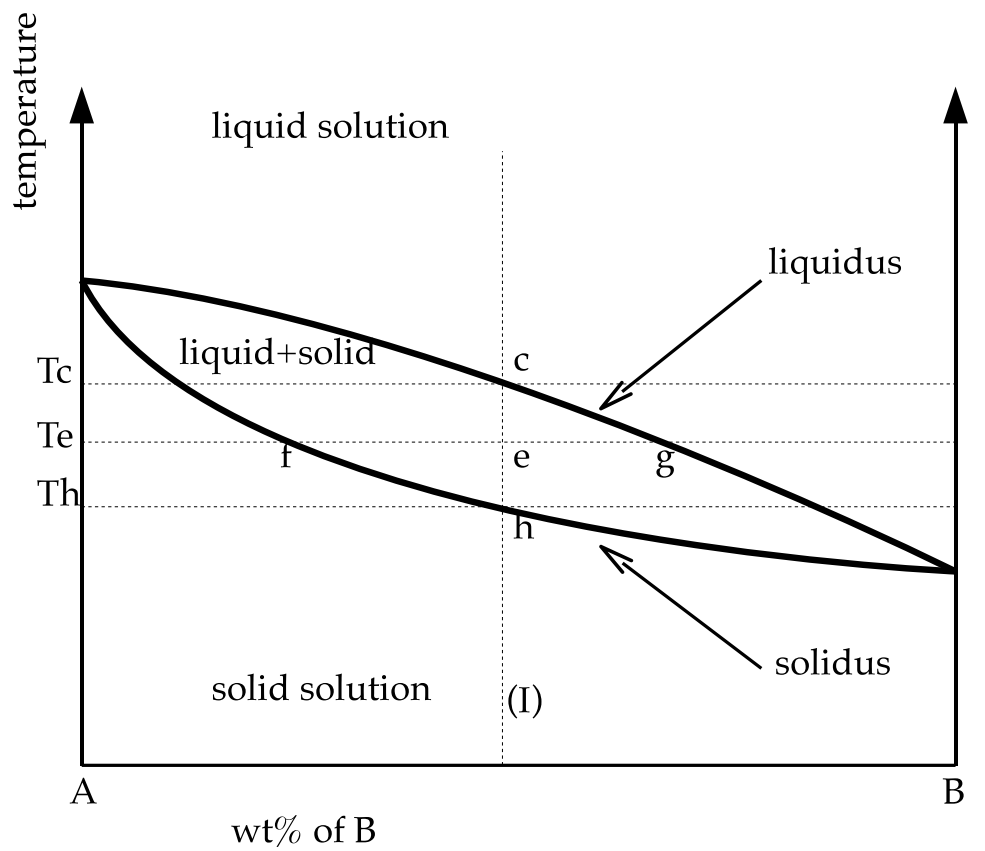

Figure 11: Binary phase diagram-Isomorphous system. 


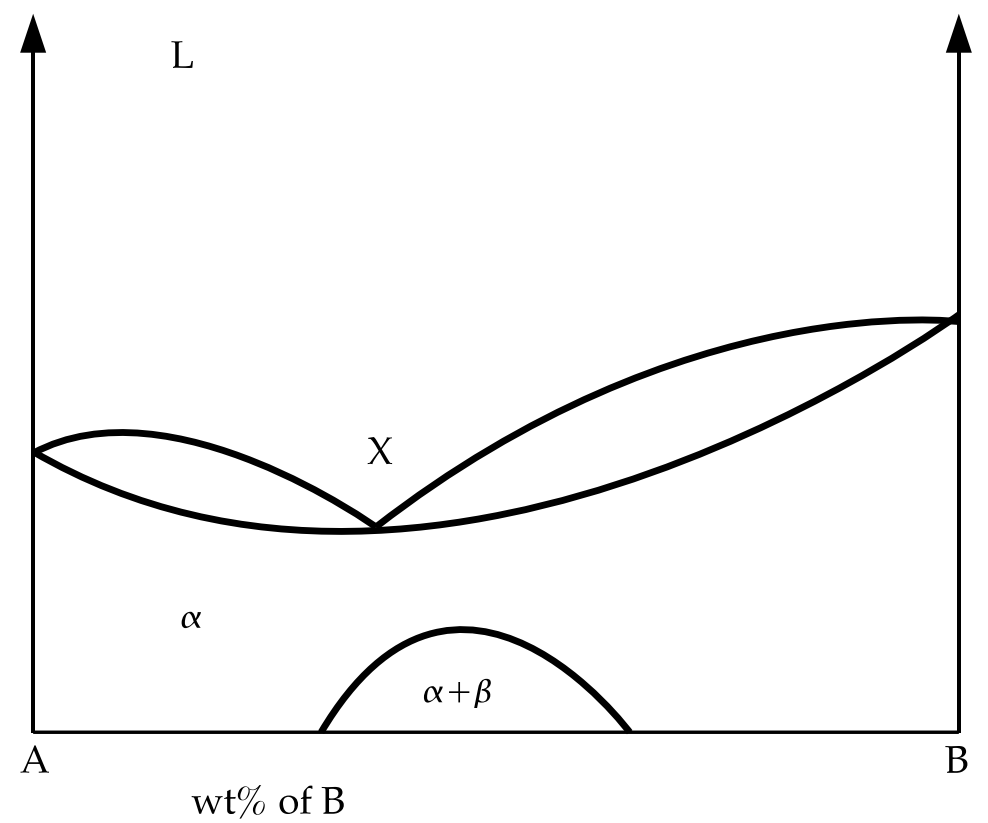

Figure 12: Binary phase diagram-Azeotropic point. 


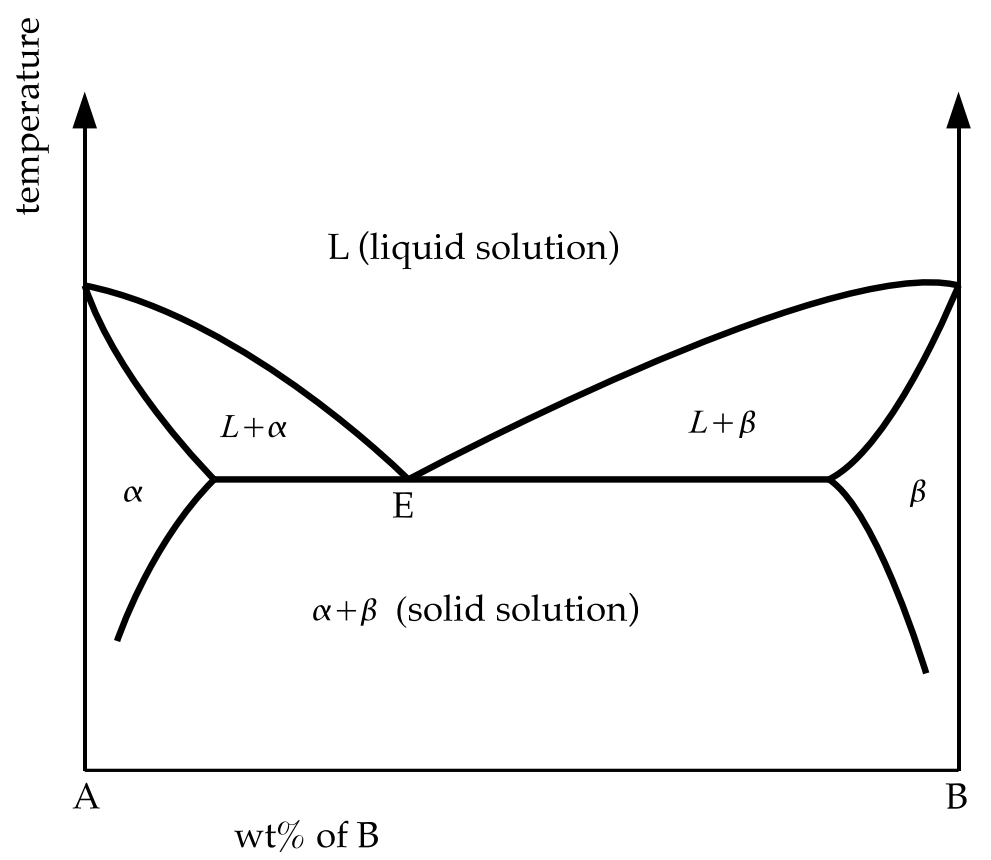

Figure 13: Binary phase diagram-Eutectic point. 


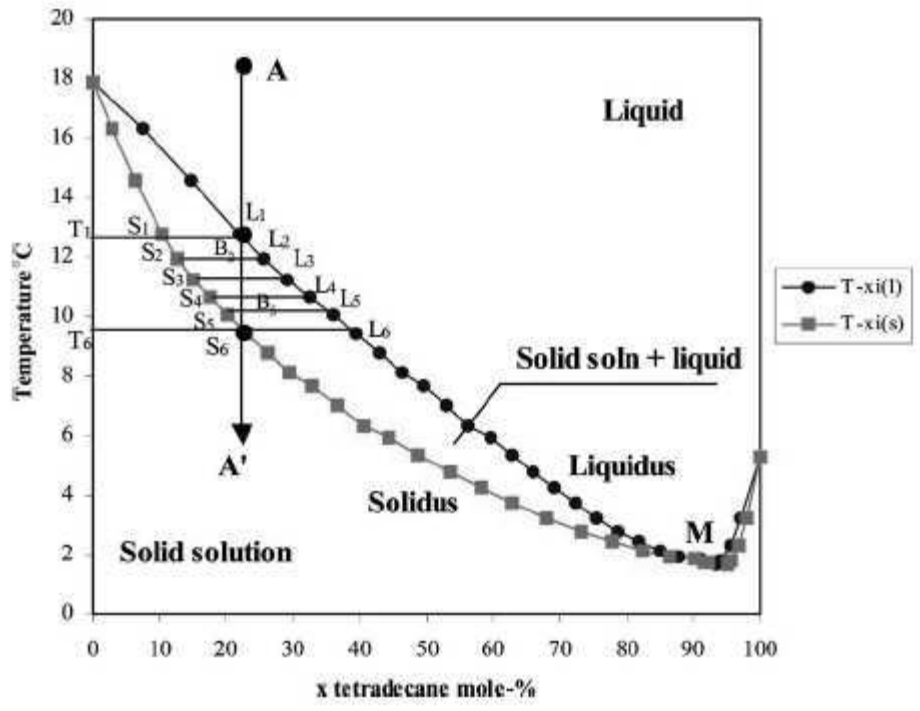

Figure 14: The liquid-solid phase diagram of binary mixtures system of $\mathrm{C}_{14} \mathrm{H}_{30}$ and $\mathrm{C}_{16} \mathrm{H}_{34}$ from [14]. 


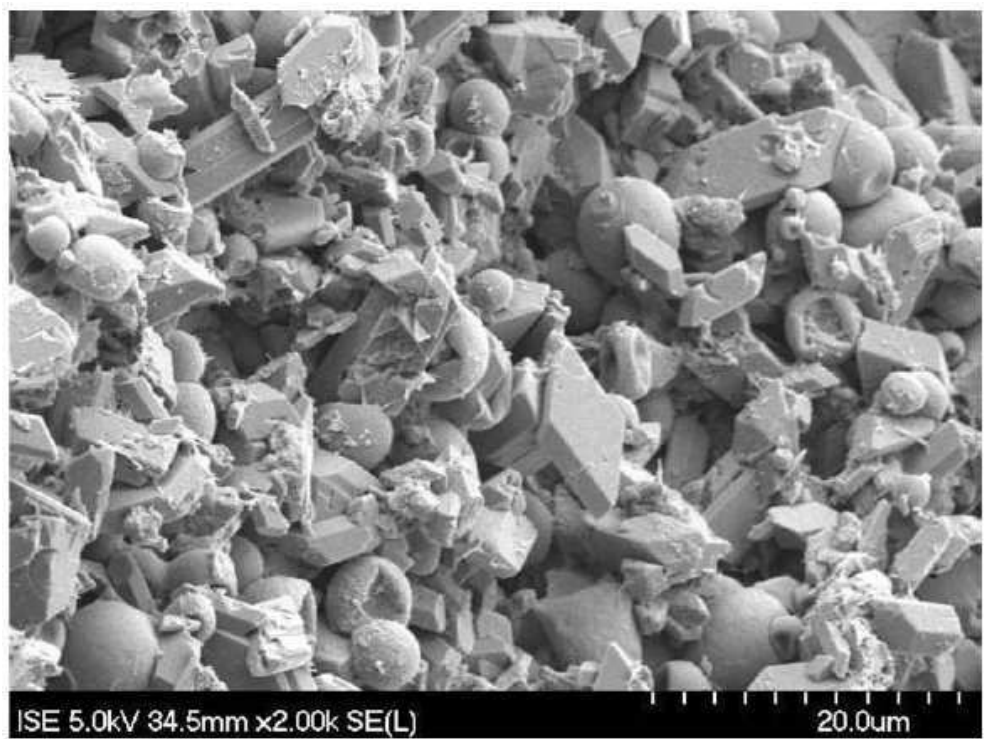

Figure 15: SEM photography of a concrete wall containing micro-encapsulated PCM, from Schossig and al. [61]. 

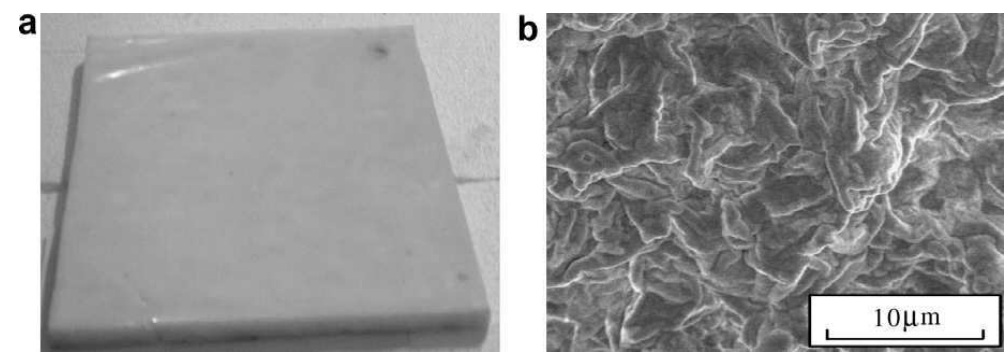

Figure 16: Photos of the shape-stabilized PCM: a) the PCM plate b) SEM picture from Zhou and al. [94]. 


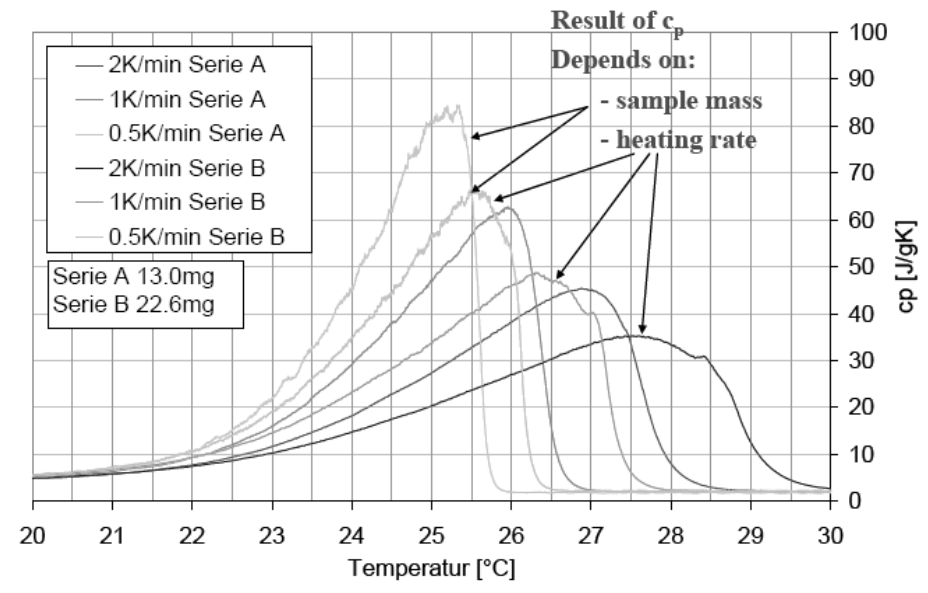

Figure 17: Temperature scanning responses depending on sample mass and heating rate from [67]. 


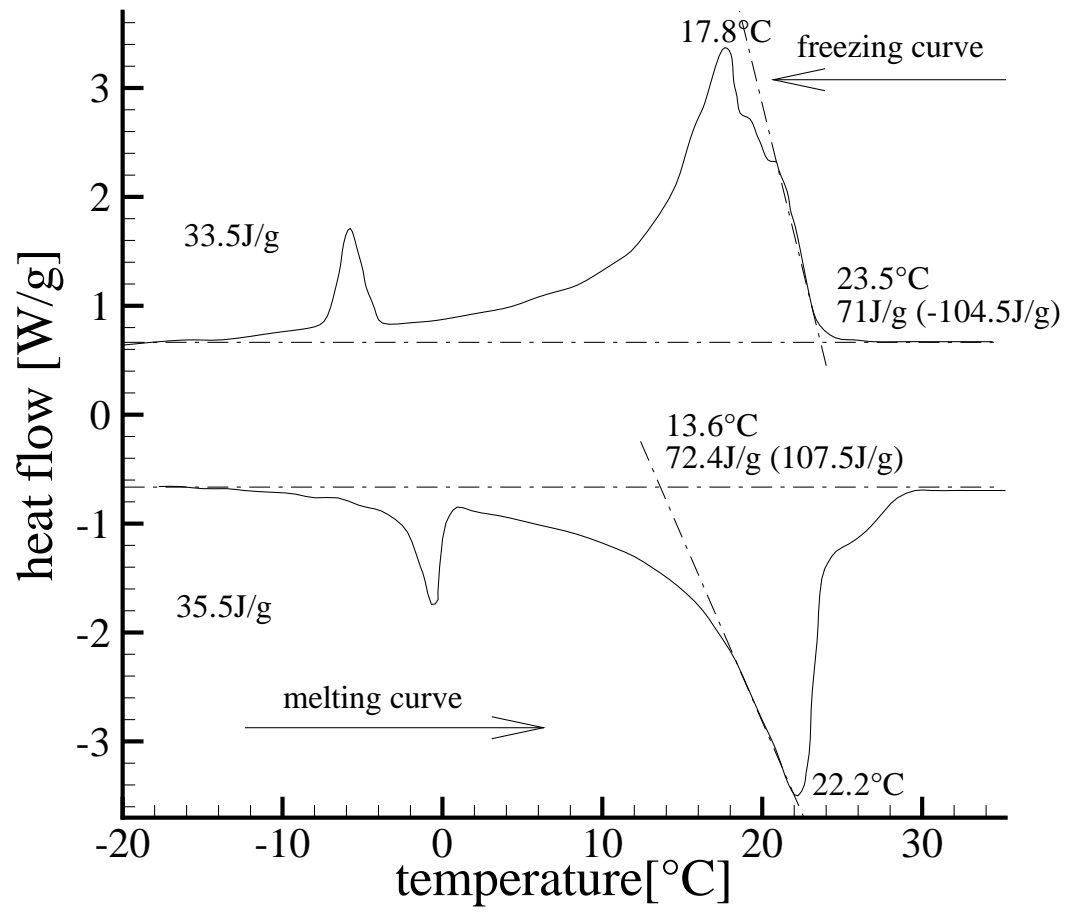

Figure 18: Differential scanning calorimeter melting and freezing curves for the composite PCM from [39]. 

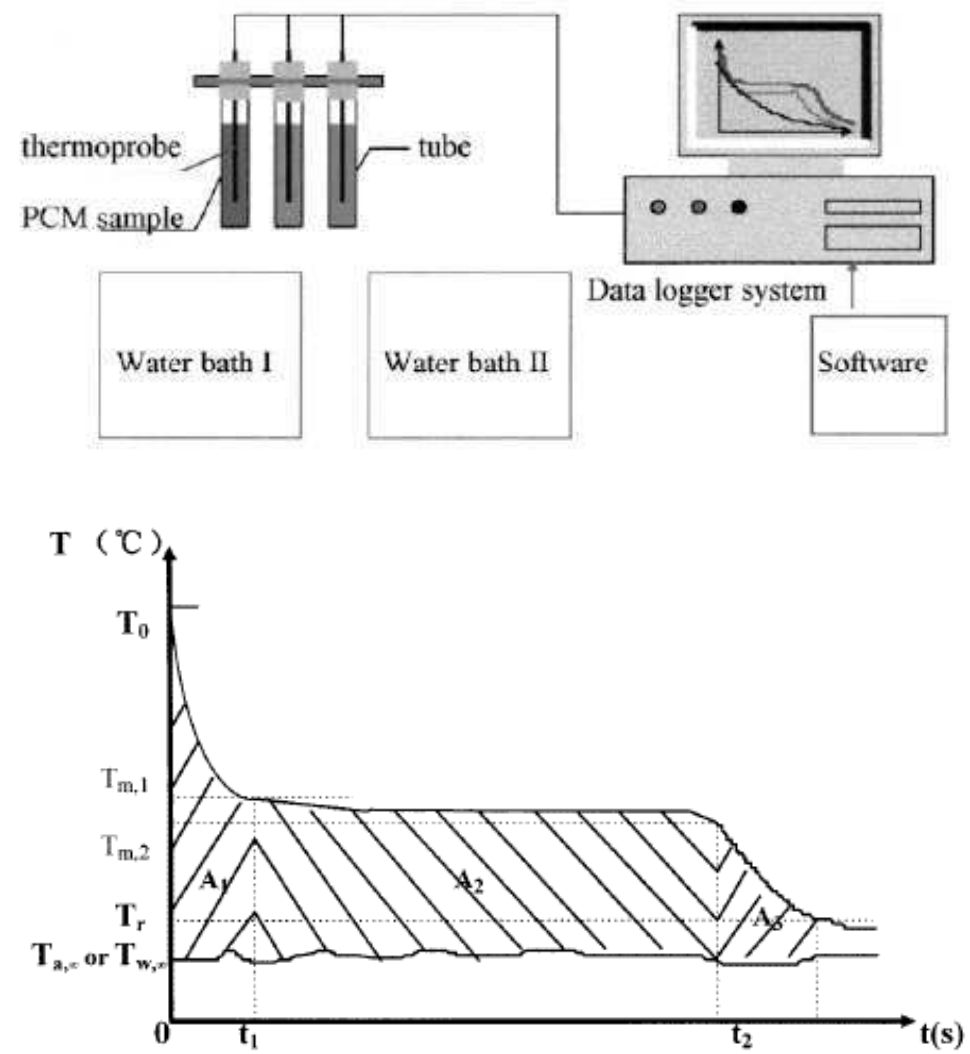

Figure 19: T-history experimental setup and T-history temperature curves. 


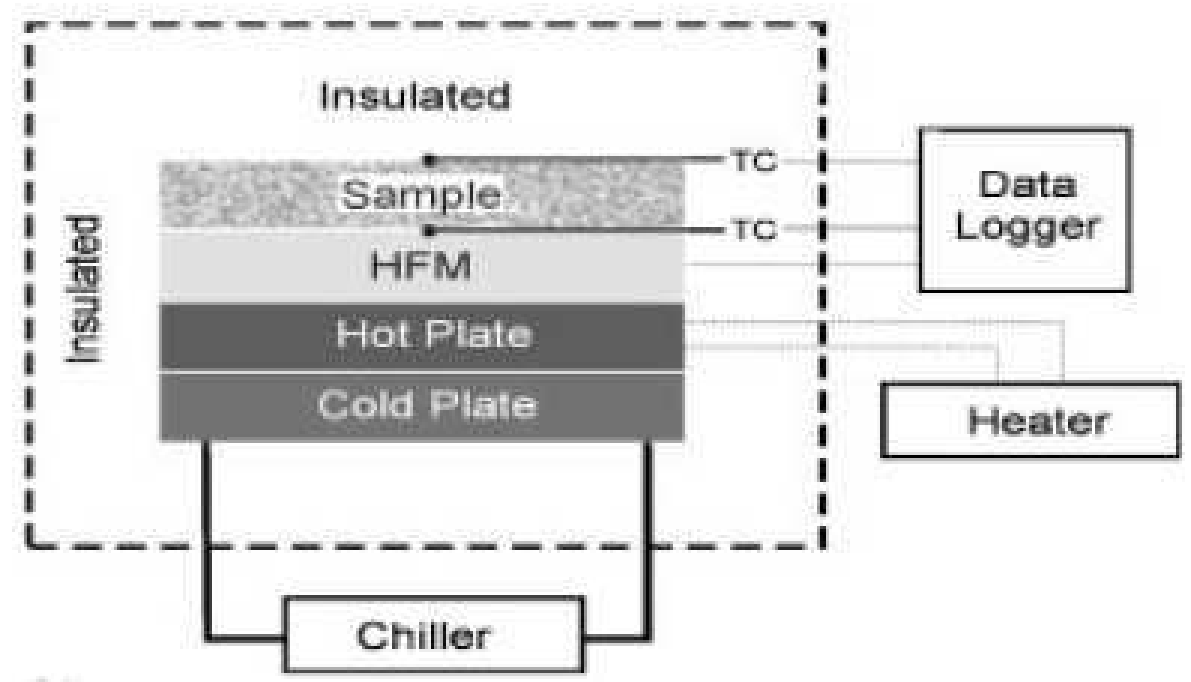

Figure 20: The measurement setup form de Darkwa et al. [71]. 